\title{
Seismic Evaluation of a Multitower Connected Building by Using Three Software Programs with Experimental Verification
}

\author{
Deyuan Zhou, Changtuan Guo, Xiaohan Wu, and Bo Zhang \\ Research Institute of Structural Engineering and Disaster Reduction, Tongji University, Shanghai, China \\ Correspondence should be addressed to Xiaohan Wu; xhwu@tongji.edu.cn
}

Received 7 July 2016; Revised 28 September 2016; Accepted 5 October 2016

Academic Editor: Miguel Neves

Copyright ( 2016 Deyuan Zhou et al. This is an open access article distributed under the Creative Commons Attribution License, which permits unrestricted use, distribution, and reproduction in any medium, provided the original work is properly cited.

\begin{abstract}
Shanghai International Design Center (SHIDC) is a hybrid structure of steel frame and reinforced concrete core tube (SF-RCC). It is a building of unequal height two-tower system and the story lateral stiffness of two towers is different, which may result in the torsion effect. To fully evaluate structural behaviors of SHIDC under earthquakes, NosaCAD, ABAQUS, and Perform-3D, which are widely applied for nonlinear structure analysis, were used to perform elastoplastic time history analyses. Numerical results were compared with those of shake table testing. NosaCAD has function modules for transforming the nonlinear analysis model to Perform-3D and ABAQUS. These models were used in ABAQUS or Perform-3D directly. With the model transformation, seismic performances of SHIDC were fully investigated. Analyses have shown that the maximum interstory drift can satisfy the limits specified in Chinese code and the failure sequence of structural members was reasonable. It meant that the earthquake input energy can be well dissipated. The structure keeps in an undamaged state under frequent earthquakes and it does not collapse under rare earthquakes; therefore, the seismic design target is satisfied. The integrated use of multisoftware with the validation of shake table testing provides confidence for a safe design of such a complex structure.
\end{abstract}

\section{Introduction}

In the recent years, a great number of high-rise buildings have been constructed in China. In some design, due to the architectural design requirements, it is unavoidable to have irregularities. However, lessons from previous earthquake damage have shown that irregular structures are more prone to be more seriously damaged than regular ones. It is usually difficult to accurately foresee the weak layer and failure pattern of a complex structure at the stage of design. Many researchers adopted theoretical approaches to evaluate seismic behaviors of complex structures [1-3], while some used testing approaches to investigate structural performances. For example, to understand the torsional effect of a complex building under earthquakes, a shake table test was conducted by Jiang and Han [4]. Lu et al. [5] adopted a scale model test to study seismic response of Shanghai World Financial Center Tower. The elastoplastic finite element model (FEM) has been used to simulate complex structures [6]. Brunesi et al. [7] adopted dynamic analyses to investigate earthquake damage of a mega-frame structure with strengthened stories.
Lu et al. [8] used ABAQUS to build a 3D FEM of a high-rise building with setbacks in elevation and obtained structural behaviors under rare earthquakes. Hedayat and Yalciner [9] conducted pushover analyses to assess seismic performance of a four-story existing building before and after strengthening. Ozdemir and Akyuz [10] employed dynamic analyses to study seismic performances of an isolated reinforced concrete building. Aly and Abburu [11] obtained seismic responses of two different high-rise buildings with the help of time history analysis. Chen and $\mathrm{Li}$ [12] created a three-dimensional (3D) FEM to evaluate seismic performances of coupled systems with a group of buildings resting on soil layers. Nguyen and Kim [13] adopted an elastoplastic dynamic finite element approach to evaluate performances of semirigid frames.

NosaCAD, ABAQUS, and Perform-3D are widely used in structural analysis [14-17]. NosaCAD is developed with ObjectARX, a development tool of AutoCAD, and it runs in the AutoCAD environment. The powerful geometric processing function of AutoCAD can be used to establish and edit structural models. ABAQUS has powerful nonlinear analysis functions. However, the preprocessor of ABAQUE is 


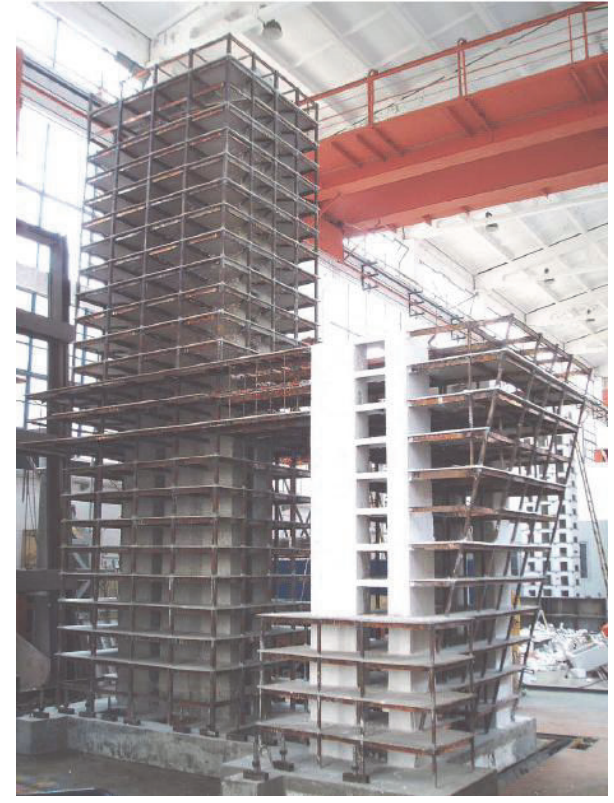

Figure 1: Model of shake table testing.

not well developed for building structure model construction. It would be time-consuming to establish a model of a complex building structure. Another software, Perform-3D, whose analysis model can be transformed from EATBS or SAP 2000, requires efforts for parameter inputs in nonlinear analyses. Two transformation modules have been developed by the authors for transforming the nonlinear analysis model from NosaCAD to ABAQUS and Perform-3D. The transformation module transforms the data of NosaCAD model, including geometry, material, load, and nonlinear parameter, into the data form of ABAQUS or Perform-3D.

In this paper, NosaCAD, Perform-3D, and ABAQUS were adopted to perform time history analyses on an irregular building called Shanghai International Design Center (SHIDC). The main elevation of SHIDC is designed as an overturned Arabic number 4. To verify structural design, it is very essential to comprehensively analyze the structure. This paper firstly built a detailed 3D FEM of this structure in NosaCAD, after which the FEM was transformed into Perform-3D and ABAQUS, respectively. Seismic analyses were carried out and numerical results were compared with those of shake table testing (Figure 1) [18].

\section{Structural Overview of the SHIDC}

2.1. Building Structure. The SHIDC is an office building that was designed by Tadao Ando, a Japanese architect. An inverted Hindu-Arabic 4 was used, which can be seen from Figures 2 and 3. A SF-RCC hybrid structure was adopted for the structure. It is composed by a 25-story tower, a 12-story tower, and a 4 -story podium. The 25 -story tower is $99 \mathrm{~m}$ high and it is called the Main Tower. The 12-story tower is $48 \mathrm{~m}$ high and called the Annex Tower. The podium is linked to the lower tower. The SF-RCC system is adopted for two towers. At the 11th floor to 13th floor of the Main Tower,

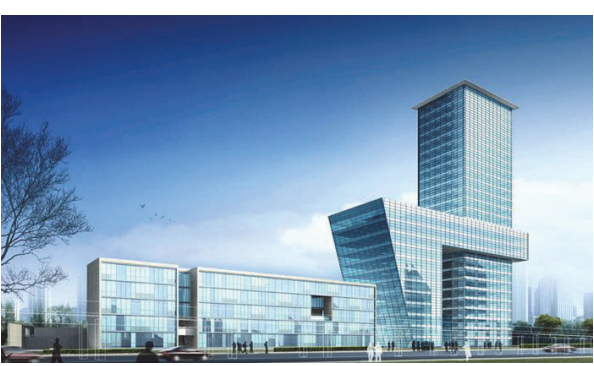

FIgURE 2: Architectural design of SHIDC.

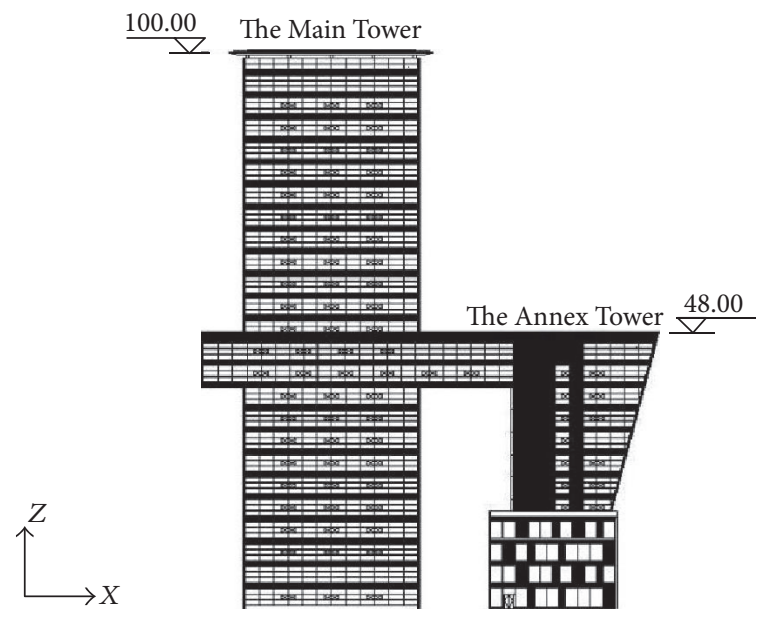

FIGURE 3: Structural elevation.

there are $7.5 \mathrm{~m}$ span cantilever floors. In the east of the lower tower, five inclined columns support cantilever beams at every floor, and the inclined angle of five columns is $15^{\circ}$. The connecting corridor is composed of $17.5 \mathrm{~m}$ steel truss spans and it provides a rigid connection between the Main Tower and the Annex Tower at the 11th floor and the 12th floor. The structural elevation and plane layout of SHIDC are shown in Figures 3 and 4 , respectively. The material parameters of the main structural members are listed in Table 1.

2.2. Structural Irregularities. In accordance with the Chinese Technical Specification for Concrete Structures of Tall Building (TSCSTB, JGJ3-2010) [19] and the Chinese Code for Seismic Design of Buildings (CSDB, GB50011-2010) [20], the structure mainly has the following out-codes instance.

(1) On the irregularities of structural plane layout: there are large openings at the 2nd floor, the 12th floor, and the 13th floor. The TSCSTB requires that the opening proportions of slabs should not exceed $30 \%$, while the opening proportions of slabs mentioned above reach beyond $30 \%$. On some floors, floor's maximum elastic interstory displacement is bigger than 1.2 times the average elastic interstory displacement of two ends of the floor. Structural layout of the Main Tower is very different from that of the Annex Tower.

(2) On the irregularities of structural elevation: the SHIDC has a structure of unequal height doubletower connecting. The number of the slant columns is 


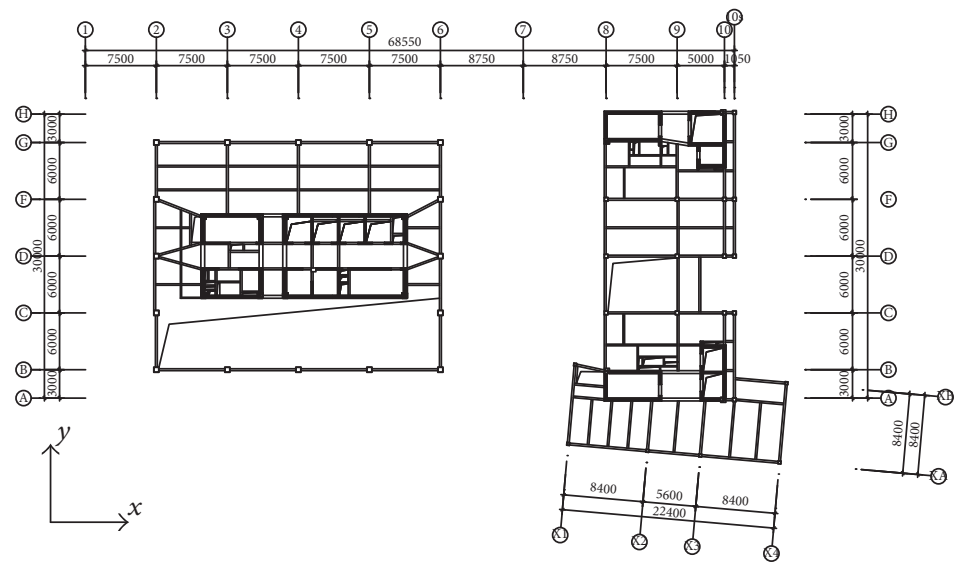

(a) The 2nd floor

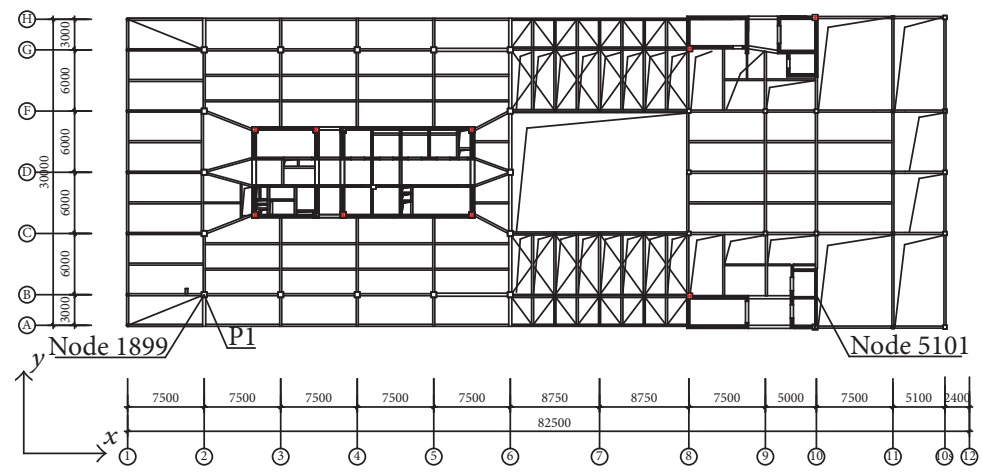

(b) The 12th floor

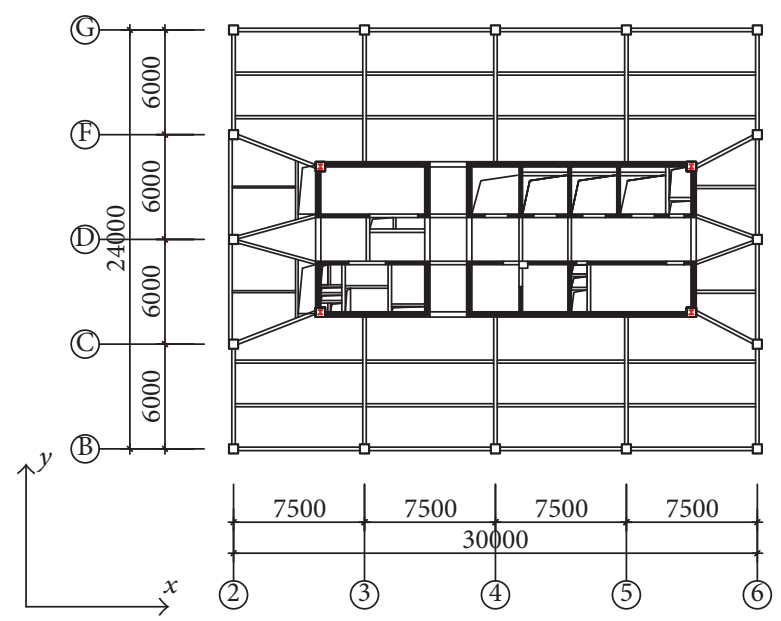

(c) Standard plan layout of the Main Tower

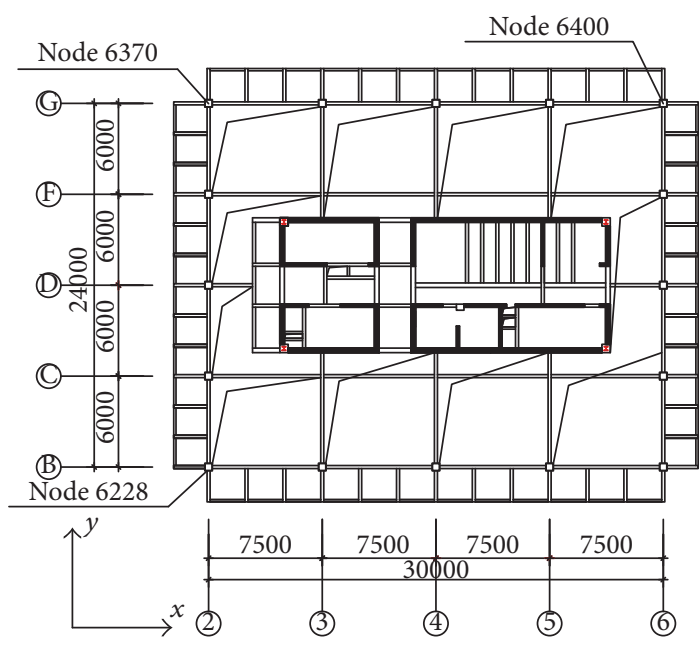

(d) Roof plan layout of the Main Tower

FIGURE 4: Standard structural plan layout. 
TABLE 1: Material properties of structural components.

\begin{tabular}{lcccc}
\hline $\begin{array}{l}\text { Location of } \\
\text { components }\end{array}$ & Material & Young's modulus & $\begin{array}{c}\text { Standard value of compressive } \\
\text { strength (Mpa) }\end{array}$ & $\begin{array}{c}\text { Standard value of tensile strength } \\
(\mathrm{Mpa})\end{array}$ \\
\hline Core tube & C30 & 30000 & 20.1 & 2.01 \\
Beam & Q235-B & 206000 & 235 & 235 \\
$\begin{array}{l}\text { Column and } \\
\text { connecting truss }\end{array}$ & Q345-B & 206000 & 345 & 345 \\
\hline
\end{tabular}

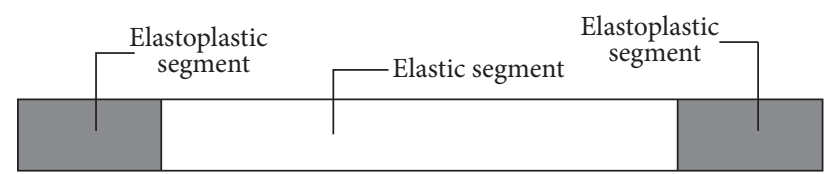

Figure 5: The frame element composed of three stiffness segments.

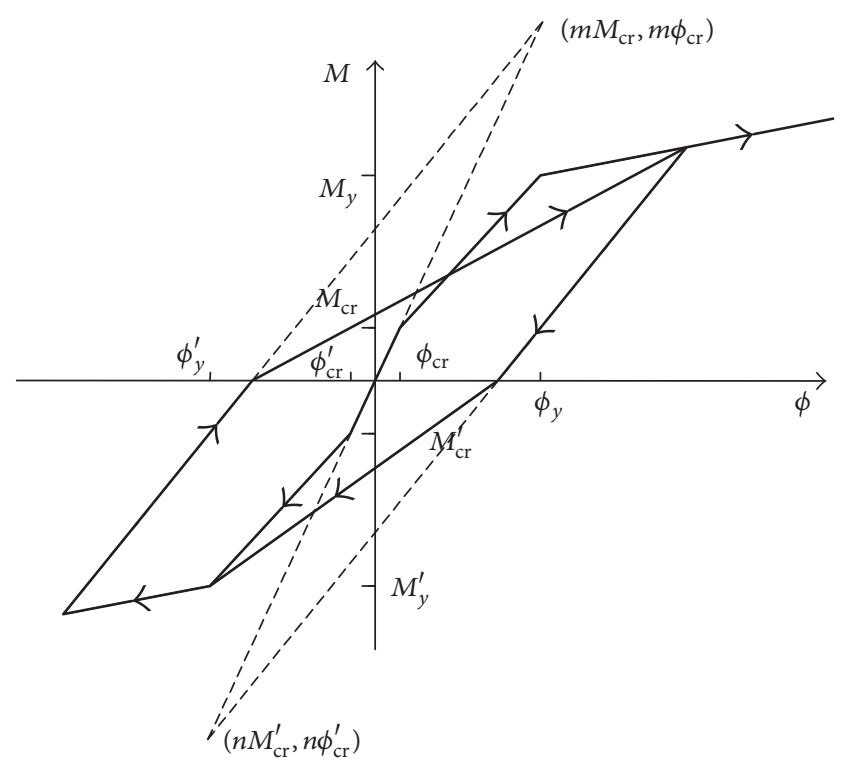

FIGURE 6: NosaCAD trilinear moment-curvature hysteretic model.

five. Lateral stiffness of some floors is not more than $70 \%$ of that of adjacent upper floor or $80 \%$ of average lateral stiffness of 3 adjacent upper floors. Setback horizontal area of 14 th floor is bigger than $25 \%$ of 13 th floor's horizontal area.

\section{FEM by Using Three Software Programs}

3.1. NosaCAD. The bar element was used in modeling the frame members and trusses. The Euler beam theory was used in the frame element. Three components constitute the bar element. Because the yielding hinge mainly occurs at the end of frame members, the component in the middle of frame element is elastic and the others can go into a yielding state (Figure 5). The components at two ends of concrete beam element employed the trilinear model (Figure 6). The steel beam element employed the bilinear moment-curvature model. For the column members that are subjected to the axial force and moment simultaneously, the components at two ends of column employed the fiber model. Figure 7 shows the concrete constitutive law for the fiber model. The rebar and steel employed the ideal elastic-plastic model, and the postyielding elastic modulus value is $1 \%$ of the initial one. The fiber model was also used to simulate the trusses.

The core wall and structural slab were simulated by the flat-shell elements containing membrane and plate [21]. The membrane and plate of flat-shell elements used in modeling the slab remain elastic. The membrane of flat-shell element used in modeling the core wall is allowed to go into nonlinear state, while the plate remains elastic. The reinforcement is dispersed in the flat-shell element. The elastoplastic constitutive model of concrete and reinforcement of flat-plate shell is identical to that in the fiber model mentioned above.

3.2. ABAQUS. The first-order 3D Timoshenko beam element (B31) was used to simulate the frame members. There are some sectional points in the cross section of B31, by which B31 can realize the function of the fiber model. The default number of sectional points of rectangular section is 25. Frame element has only one integral section along the element. In order to reflect different deformation and nonlinear stiffness along the element, one frame member was normally divided into 3 to $6 \mathrm{~B} 31$ elements. It is difficult to deal with the line load on frame member in ABAQUS and the line load was converted into node loads, which were added on the nodes at the segment ends.

The core wall was simulated by the reduced-integration shell element of quadrangle (S4R), while the structural slab was modeled by the reduced-integration shell element of quadrangle or triangle (S4R or S3R). Some sectional points were distributed along the sectional direction, by which the shell element can realize the function of multilayer shell element for nonlinear analyses. The default number of sectional points is 5 .

There are two ways to simulate rebar in concrete. On the one hand, rebar can be embedded in concrete, by which the deformation of rebar is consistent with concrete. The rebar in core wall and structural slab was simulated following this way. On the other hand, since ABAQUS/Explicit does not support the method for reinforcement bar embedded in frame element, the rebar is equivalent to a box steel element with the same area, after which the tube element and the concrete element possess the same nodes (Figure 8). The second way is used to simulate the rebar in frame members.

The ideal elastoplastic model given in ABAQUS was used to describe nonlinear properties of rebar in the wall and slab. The nonlinear properties of concrete in shear wall were 


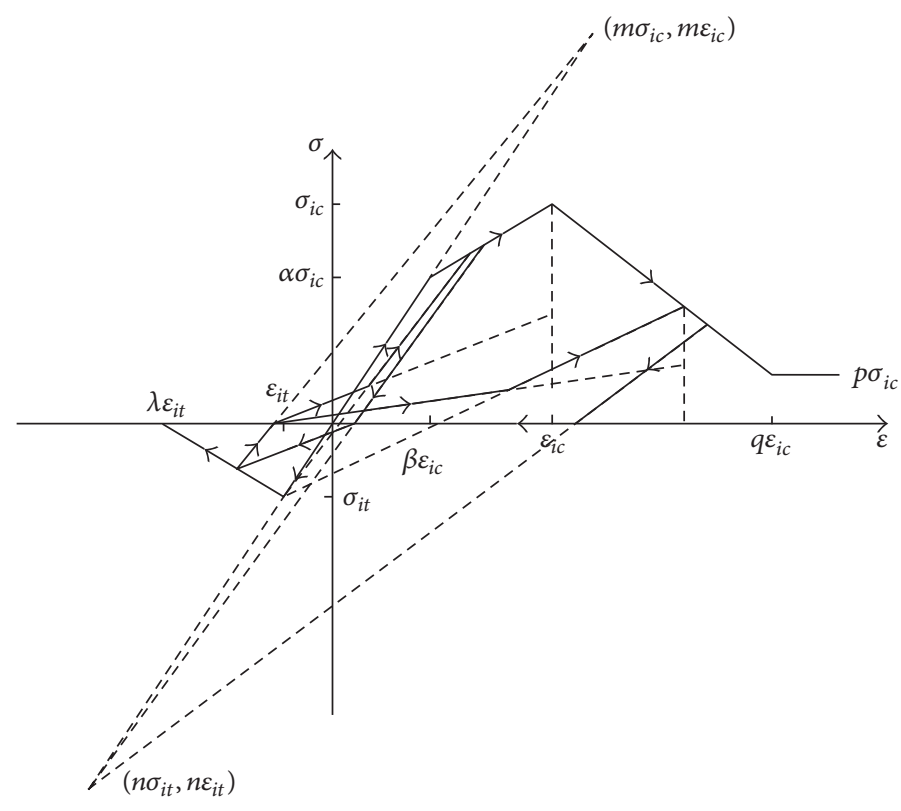

Figure 7: NosaCAD concrete constitutive model.

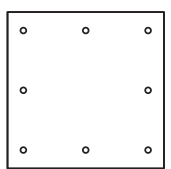

FIGURE 8: Reinforcement model for frame element. described by the plastic-damage model based on ABAQUS. The plastic-damage model of concrete employed the conceptions of isotropic damaged elasticity combing isotropic tensile and compressive plasticity to present the nonlinear properties. The stress-strain relationship of concrete under cyclic loads is shown in Figure 9. In the figure, $W_{c}$ and $W_{t}$ are the compressive and tensile stiffness recovery factor controlling the recovery of compressive and tensile stiffness as the loading direction reverses.

Because the explicit analysis module in ABAQUS does not allow the bar element, which is used to simulate beam and column, to adopt the elastoplastic material model given in ABAQUS, user material subroutines that can be used by ABAQUS software were developed. The constitutive relation of concrete and steel in user material subroutines is identical with that in NosaCAD (Figure 7).

3.3. Perform-3D. Similarly, as in NosaCAD, the trilinear and bilinear moment-curvature hysteretic models were used to simulate the concrete and steel beams. The elastoplastic properties of columns were modeled by the fiber model. Unlike the elastoplastic frame member in NosaCAD, which is composed of two elastoplastic segments and one elastic segment in the middle, the elastoplastic frame member in Perform-3D is composed of elastic segment and elastoplastic segment in arbitrary formation. In this paper, a frame member in Perform-3D also consists of three components: one is linear elastic and the others are elastoplastic. Their distribution is the same as that in NosaCAD.

Shear wall was simulated by the macroscopic wall element. The element not only contains a vertical and a horizontal fiber layer considering the nonlinear properties of materials but also possesses a shear layer of concrete in elastic.

The steel model that ignores buckling was used to simulate the rebar and truss. Concrete constitutive relation considering Mander stress-strain relationship should be transferred in the action-deformation relationship of Perform-3D which can be determinate by 5 parameters and strength loss was taken into account. The moment-curvature hysteretic relationship for frame element section was also defined by the action-deformation relationship of Perform-3D, which can be determinate by 3 parameters or 5 parameters.

In NosaCAD and ABAQUS, the wall element has rotational stiffness in plane at a node. Perform-3D wall element has no such stiffness. The embedded rigid beam should be added in NosaCAD environment before model transformation to coordinate the deformation between the wall and coupling beam in Perform-3D model (Figure 10).

3.4. FEM of the Structure. Models in NosaCAD, ABAQUS, and Perform-3D (Figure 11) are all based on the assumptions as follows: (1) the bottom of basement was regarded as the fix end; (2) the calculated mass of the model was composed of $100 \%$ dead load, $100 \%$ additional dead load, and $50 \%$ live load.

The mass in NosaCAD was 281,000 tons, while in Perform-3D it was 271,000 tons and in ABAQUS was 281,000 tons, which shows little difference. Figures 11(a), 11(b), and 11(c) show the model in NosaCAD, the model in ABAQUS, and the model in Perform-3D, respectively.

3.5. Earthquake Inputs. According to the TSCSTB, no less than two natural waves and an artificial wave should be used 


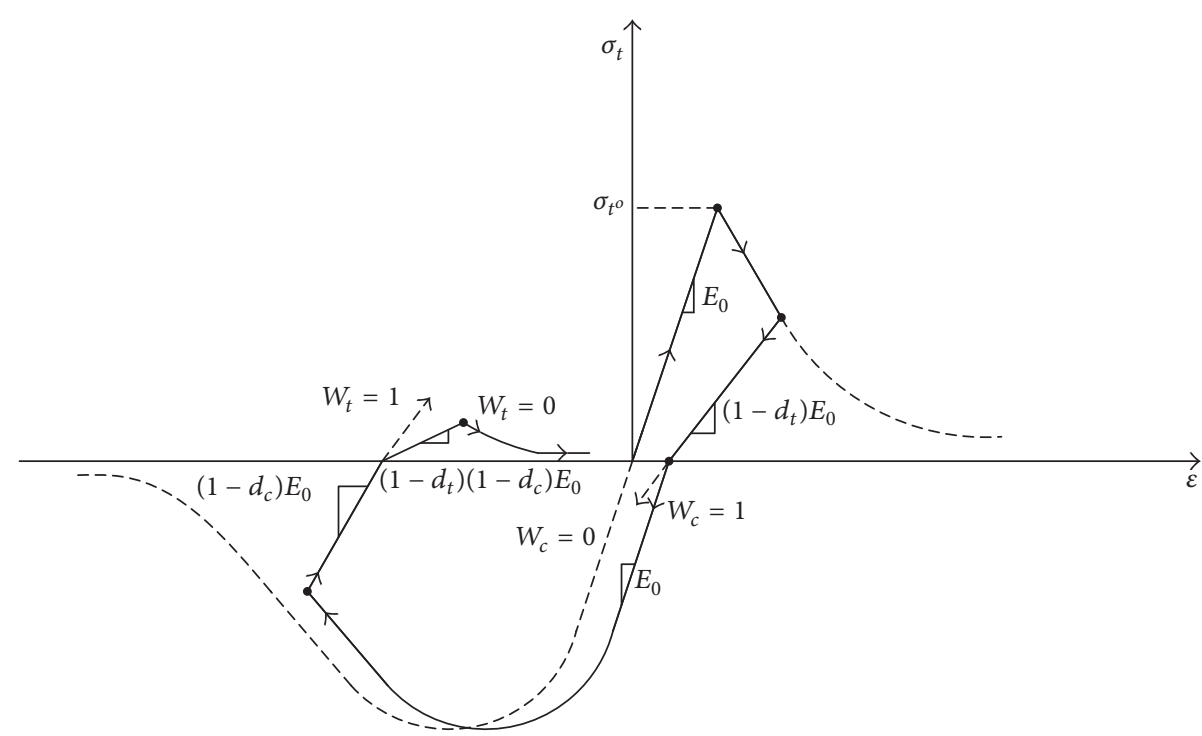

Figure 9: Uniaxial load cycle (tension-compression-tension) assuming $W_{c}=1$ and $W_{t}=0$.

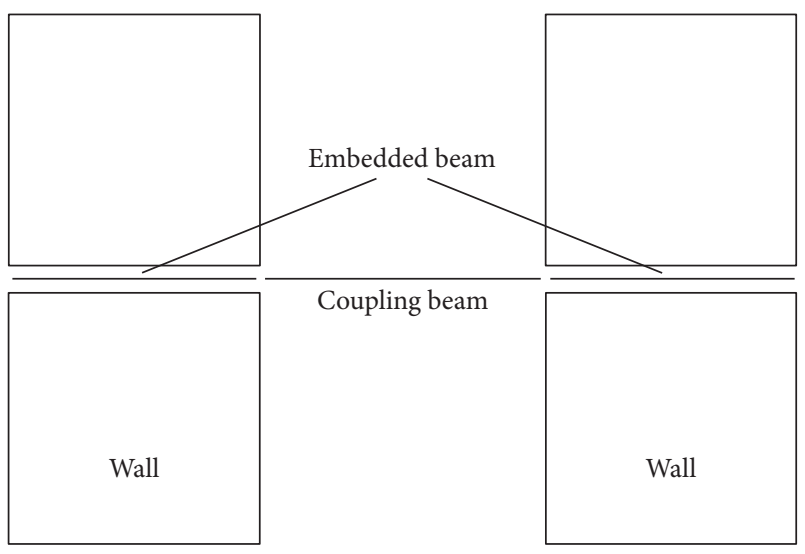

FIgure 10: Connection between wall and coupling beam in Perform-3D.

in the nonlinear time history analysis. Three different earthquake waves were used in nonlinear time history analyses: (a) the Pasadena wave; (b) the El-Centro wave; and (c) the Shanghai synthetic wave (SHW2) according to the Shanghai CSDB [22] (DGJ08-9-2003). Figure 12(a) provides acceleration time history data of SHW2. The response spectrum of SHW2 (normalized to $0.22 \mathrm{~g}$ ) was also compared with that of designing spectrum (Figure 12(b)), in which the damping ratio is 0.05 .

In accordance to the CSDB, structures in earthquake regions should resist frequent, moderate, and rare earthquakes, corresponding to exceedance probabilities of $63.2 \%$, $10 \%$, and $2 \%$ in half a century, respectively. Because Shanghai pertains to the 7-degree seismic intensity region, the corresponding peak ground accelerations (PGAs) of frequent, moderate, and rare earthquakes are $0.035 \mathrm{~g}, 0.100 \mathrm{~g}$, and $0.220 \mathrm{~g}$, respectively.

Seismic behaviors under minor and major earthquakes are the most important in structural design. The PGAs of the chosen ground motions were scaled to the corresponding values of frequent and rare earthquakes, respectively. In order to compare numerical analysis with shake table testing, during the analysis, the Pasadena and El-Centro earthquake waves were inputted in $X$ and $Y$ directions simultaneously. (the N-S accelerogram is inputted in $Y$ direction), and the ratio of PGA in $X$ direction to PGA in $Y$ direction is $0.85: 1$. The artificial wave was inputted in single horizontal principal direction. According to TSCSTB, the structural damping ratio corresponding to hybrid structural system is 0.04 .

\section{Comparison of Experimental and Numerical Results}

4.1. Natural Vibration Properties. Free vibration results obtained by different software and shake table testing were given in Table 2. As shown from the table, the first six-order periods in NosaCAD show good agreement with those from Perform-3D and ABAQUS. The sequence of vibration mode in NosaCAD, Perform-3D, ABAQUS, and experimental results is identical. Natural periods of numerical results are a little bit different from those of shake table testing results. The values from shake table testing are higher than those from numerical analyses. Due to the difference between the two towers, the fundamental vibration mode has a torsion composition. In Figure 13, the first three vibration modes in NosaCAD were given.

The Main Tower and the Annex Tower's first six modes calculated by NosaCAD were listed in Table 3. As shown in the table, the first three vibration mode shapes of two towers are uniform. By comparing Tables 2 and 3, natural vibration period of the global system, which is very different from that of the Annex Tower, is close to that of the Main Tower.

4.2. Roof Displacement. Nodes 1899, 5101, 6228, 6370, and 6400 , which, respectively, locate in the connecting floor and roof corner (Figures 4(c) and 4(d)), were chosen to investigate 


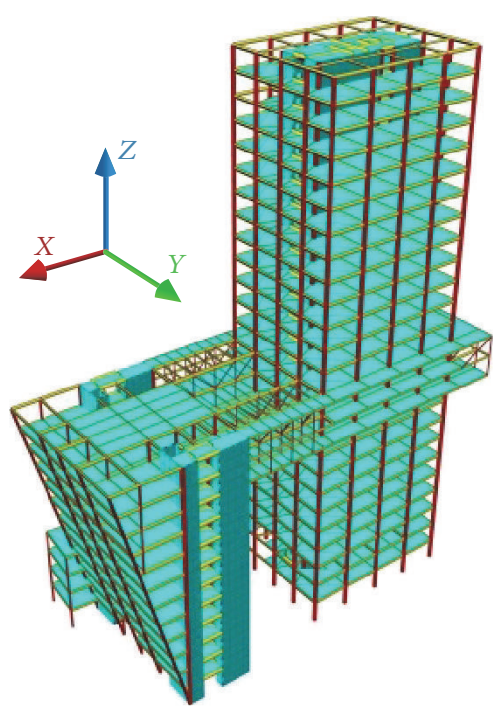

(a) NosaCAD model

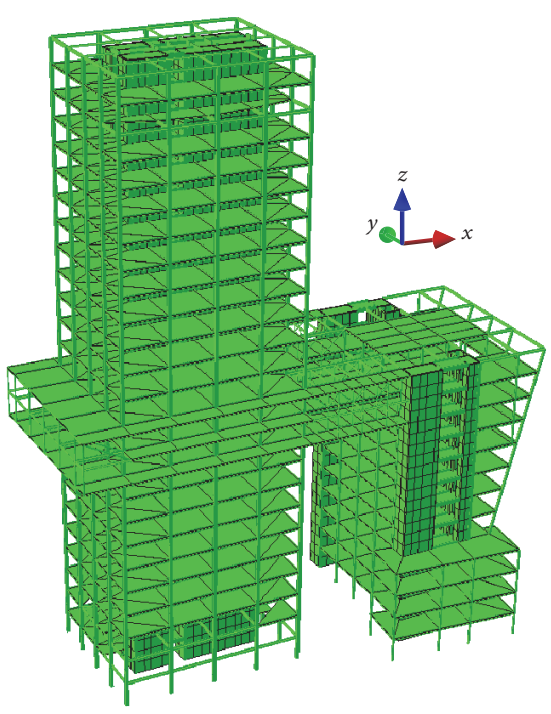

(b) ABAQUS model

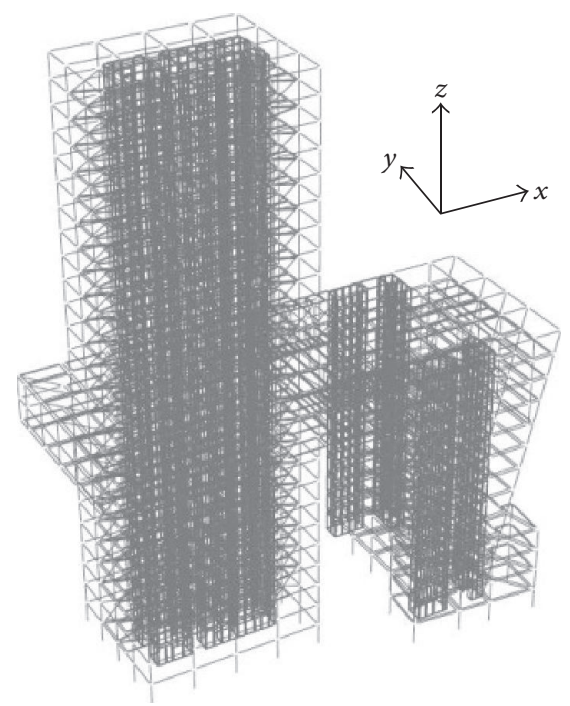

(c) Perform-3D model

FIGURE 11: The models of structure.

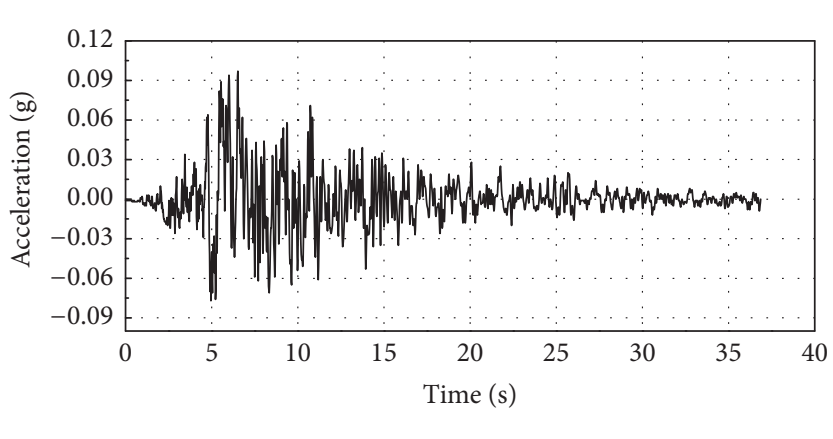

(a) Time history

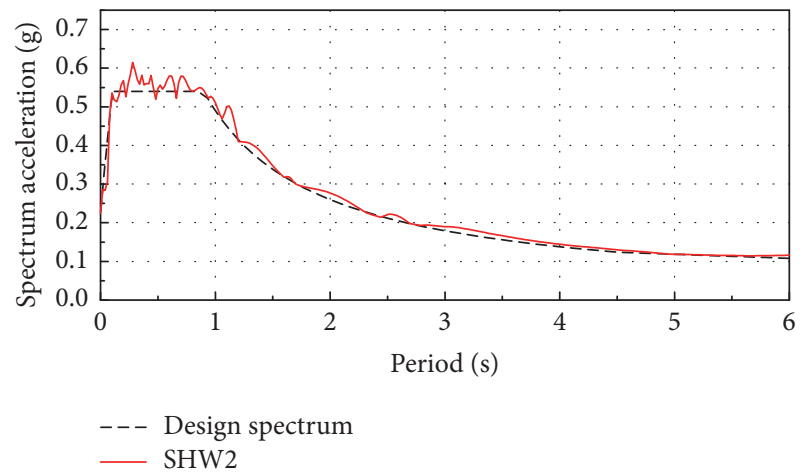

(b) Spectrum acceleration

FIGURE 12: SHW2 earthquake wave.

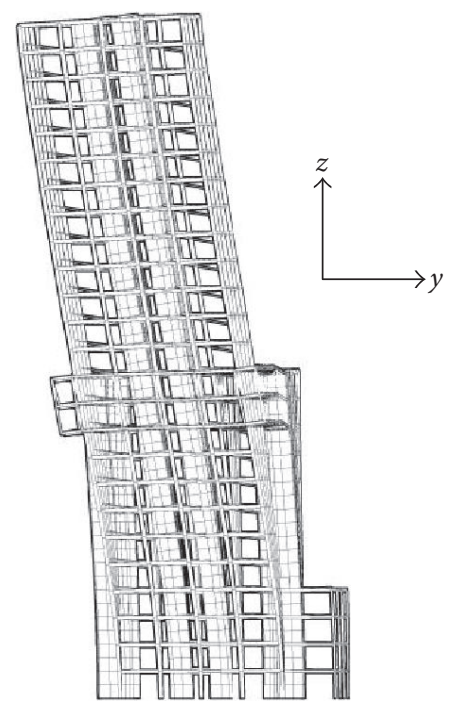

(a) 1st mode

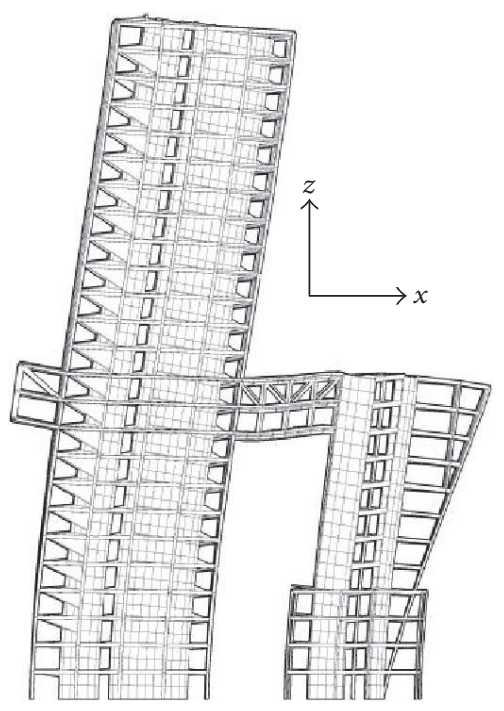

(b) 2nd mode

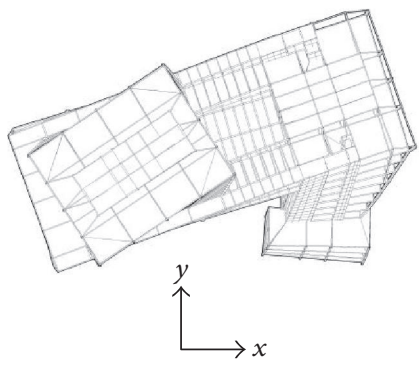

(c) 3rd mode

Figure 13: First three mode shapes in NosaCAD. 
TABLE 2: Natural vibration periods of the structure.

\begin{tabular}{|c|c|c|c|c|c|}
\hline \multirow{2}{*}{ Order } & \multicolumn{4}{|c|}{ Period(s) } & \multirow{2}{*}{ Description } \\
\hline & NosaCAD & ABAQUS & Perform-3D & Test & \\
\hline$(1)$ & 2.29 & 2.30 & 2.19 & 2.57 & Translation in $Y$ with torsion \\
\hline (2) & 1.30 & 1.34 & 1.29 & 1.71 & Translation in $X$ \\
\hline (3) & 1.12 & 1.11 & 1.03 & 1.21 & Torsion \\
\hline (4) & 0.71 & 0.68 & 0.61 & 0.73 & Second translation in $Y$ with torsion \\
\hline (5) & 0.58 & 0.55 & 0.49 & 0.59 & Second translation in $X$ \\
\hline (6) & 0.40 & 0.41 & 0.39 & 0.47 & Second Torsion \\
\hline
\end{tabular}

TABle 3: Natural vibration periods of the Main Tower and Annex Tower.

\begin{tabular}{|c|c|c|c|c|}
\hline \multirow{2}{*}{ Order } & \multicolumn{2}{|c|}{ The Main Tower } & \multicolumn{2}{|c|}{ The Annex Tower } \\
\hline & $\operatorname{Period}(\mathrm{s})$ & Description & Period(s) & Description \\
\hline (1) & 2.36 & Translation in $Y$ & 1.05 & Translation in $Y$ \\
\hline (2) & 1.33 & Translation in $X$ & 0.97 & Translation in $X$ \\
\hline (3) & 1.20 & Torsion & 0.74 & Torsion \\
\hline (4) & 0.61 & Second translation in $Y$ & 0.26 & Local vibration of roof \\
\hline (5) & 0.39 & Second translation in $X$ & 0.24 & Local vibration of roof \\
\hline (6) & 0.33 & Second torsion & 0.23 & Second torsion \\
\hline
\end{tabular}

the structural displacement. For the high-rise building located in 7 seismic intensity areas, seismic responses are relatively large. There is a large difference among seismic responses of three different earthquake records under the same PGA.

Figure 14 provides the roof displacement time history of node 6228, which was generated by Pasadena under rare intensity 7 earthquakes. It can be found that the displacement response of NosaCAD is close to that of Perform-3D not only in amplitude but also in step. But there are some differences between ABAQUS and NosaCAD. The results of ABAQUS are smaller than those of the other two software programs. The maximum roof displacement of NosaCAD, Perform$3 \mathrm{D}$, and ABAQUS in $X$ direction is $91.6 \mathrm{~mm}, 89.4 \mathrm{~mm}$, and $56.8 \mathrm{~mm}$, respectively. The maximum roof displacement of NosaCAD, Perform-3D, and ABAQUS in $Y$ direction is $114.6 \mathrm{~mm}, 115.7 \mathrm{~mm}$, and $70.7 \mathrm{~mm}$, respectively.

The roof displacement time history of nodes 6370 and 6400 under El-Centro of rare intensity is shown in Figure 15. As shown in Figure 15, the responses of two nodes are nearly identical in the $X$ direction, while there is some difference in the $Y$ direction. The maximum displacement difference is $136.4 \mathrm{~mm}$, and the corresponding torsion angle is $4.9 \times$ $10^{-3} \mathrm{rad}$. The displacement time history of nodes 1899 and 5101 under El-Centro of rare intensity is shown in Figure 16. Nodes 1899 and 5101 are both in the connecting floor. As shown in Figure 16, the responses of two nodes show some difference in the $Y$ direction. The maximum displacement difference is $174.8 \mathrm{~mm}$, and the corresponding torsion angle is $2.9 \times 10^{-3} \mathrm{rad}$.

The difference between nodes 1899 and 5101 reflects the unsynchronized response of the two towers. Because of the differences of height and story lateral stiffness between the two towers, the torsion effect of structure was motivated. The torsion effect on the roof is more severe than that on the connecting floor.

4.3. Story Displacement. The string of nodes along the vertical direction at the corner column of the Main Tower P1 (Figure 4(b)) was chosen to investigate the structural distortion, which is the same as the shake table testing. Figures 17 and 18 show the story displacement envelopes under minor earthquakes and major earthquakes. As can be seen, an obvious weak story does not exist in the major structure. The story displacement in the $Y$ direction is bigger than that in the $X$ direction. The reason can be attributed to the connecting corridor in the $X$ direction, which results in that the lateral stiffness in the $X$ direction is bigger than that in the $Y$ direction. The story displacement response envelopes of NosaCAD are consistent with those of ABAQUS and Perform-3D not only in trend but also in amplitude. The numerical results are very close to those of shake table testing, especially under minor earthquakes. When the structure suffers major earthquakes, with the structure coming into nonlinear state, the results' difference between numerical analyses and experiments results is bigger. There is a little difference in amplitude but the trend is nearly the same. Under frequent intensity earthquakes, the maximum story displacement of NosaCAD, ABAQUS, Perform-3D, and experiment in the $X$ direction is $42.57 \mathrm{~mm}, 40.13 \mathrm{~mm}, 47.87 \mathrm{~mm}$, and $34.79 \mathrm{~mm}$, respectively. In the $Y$ direction, the maximum story displacement is $90.53 \mathrm{~mm}, 86.92 \mathrm{~mm}, 95.82 \mathrm{~mm}$, and $97.98 \mathrm{~mm}$, respectively. Under rare intensity earthquakes, the maximum story displacement of NosaCAD, ABAQUS, Perform-3D, and experiment in the $X$ direction is $356.67 \mathrm{~mm}$, $317.56 \mathrm{~mm}, 391.34 \mathrm{~mm}$, and $278.85 \mathrm{~mm}$, respectively. In the $Y$ direction, the maximum story displacement is $619.31 \mathrm{~mm}$, $592.63 \mathrm{~mm}, 642.0 \mathrm{~mm}$, and $581.04 \mathrm{~mm}$, respectively. 


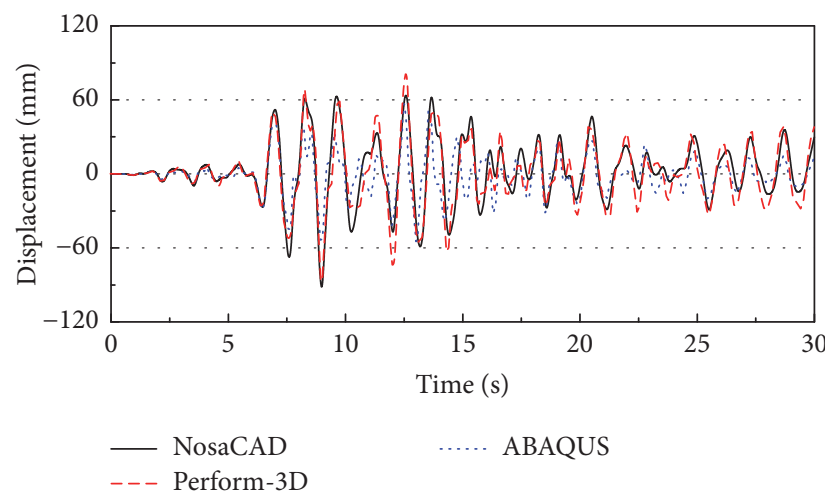

(a) Displacement time history in direction $X$

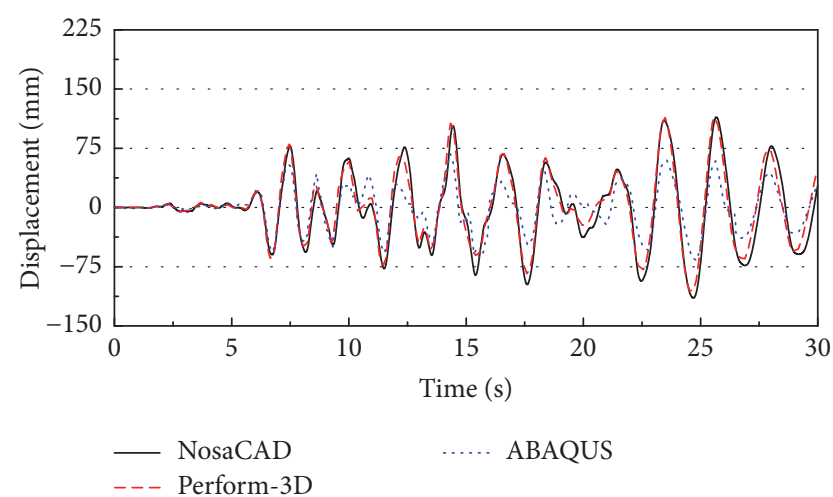

(b) Displacement time history in direction $Y$

FIGURE 14: Displacement of node 6228 under Pasadena of rare intensity.

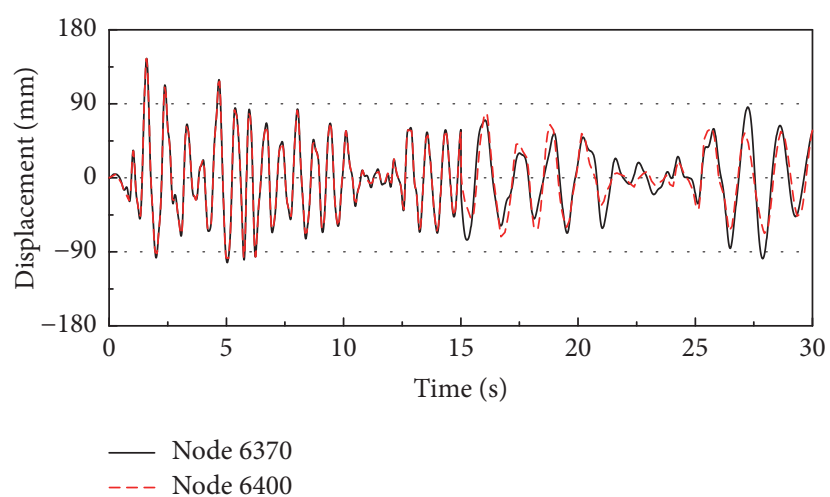

(a) Displacement time history in direction $X$

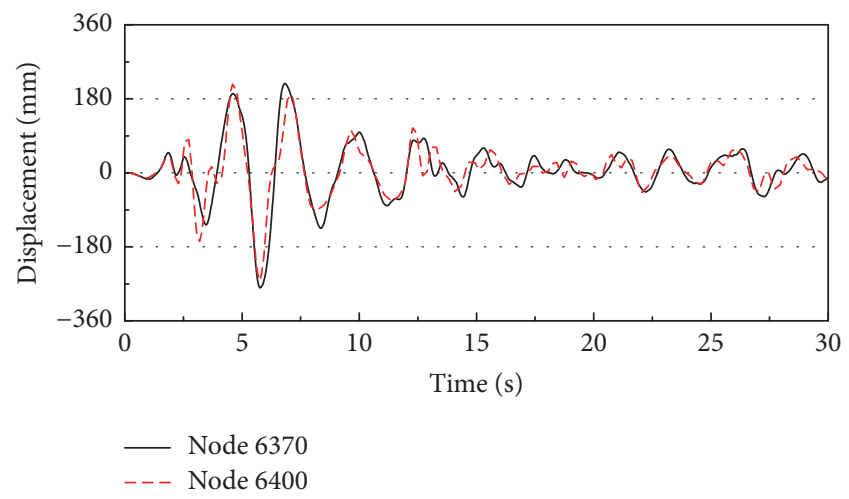

(b) Displacement time history in direction $Y$

FIGURE 15: Displacement of node 6370/6400 under El-Centro of rare intensity.

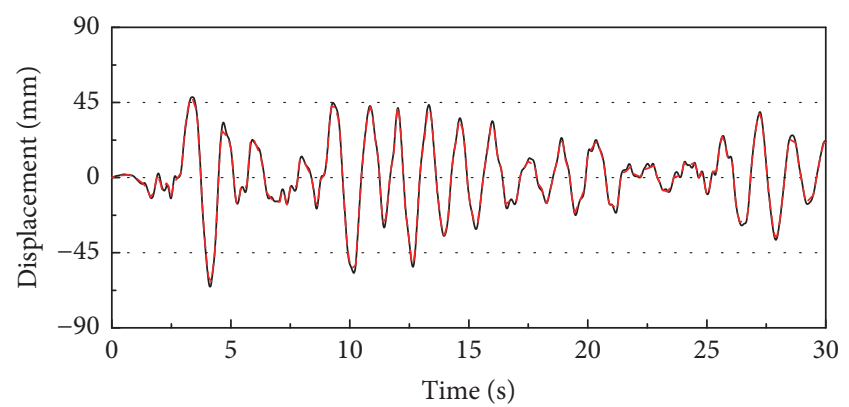

- Node 1899

(a) Displacement time history in direction $X$

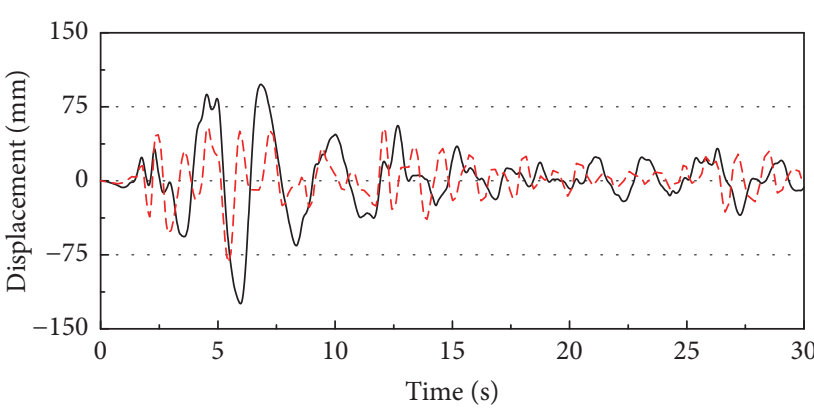

- Node 1899

(b) Displacement time history in direction $Y$

FIGURE 16: Displacement of node 1899/5101 under El-Centro of rare intensity.

4.4. Interstory Drift. Figures 19 and 20 show the interstory drift envelopes under minor earthquakes and major earthquakes. As can be seen, calculation results from NosaCAD show an agreement with those of ABAQUS and Perform3D. Envelopes of finite element analysis are a little different from those from experiments. The trends of envelope curves in three software programs and experiments are nearly the same. Under rare intensity, the interstory drifts of three software programs and experiments in the $X$ direction regress near the twelfth floor. The reason for this change may be attributed to the fact that the connecting corridor in the $X$ direction increases the direction's lateral stiffness along the height. By comparing Figures 19 and 20, because of the development of structural plastic deformation below the 


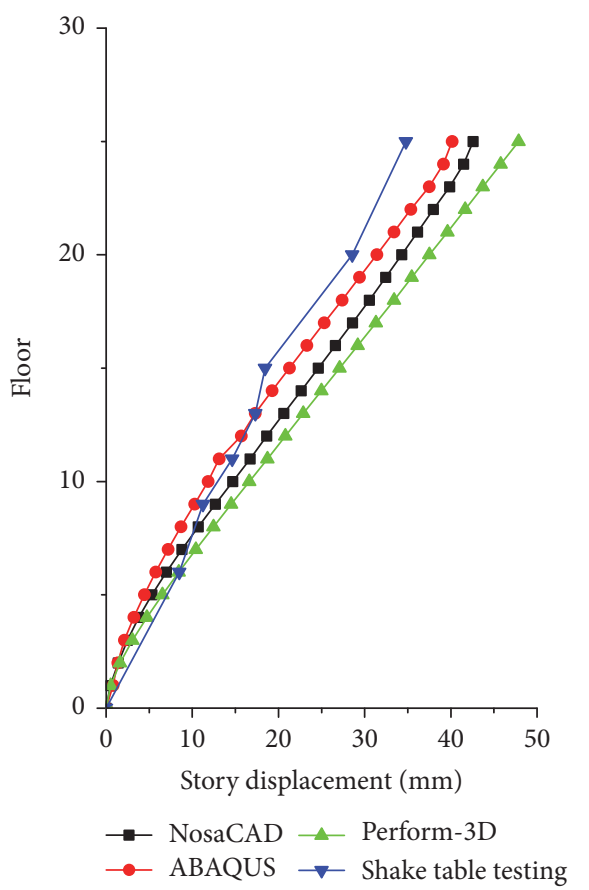

(a) In direction $X$

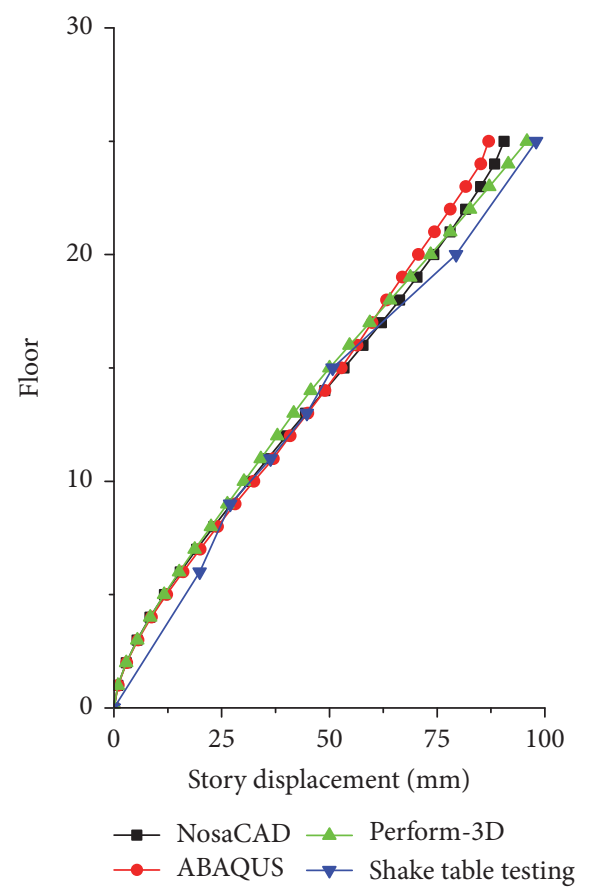

(b) In direction $Y$

FIGURE 17: Story displacement envelopes under frequent intensity 7 earthquakes.

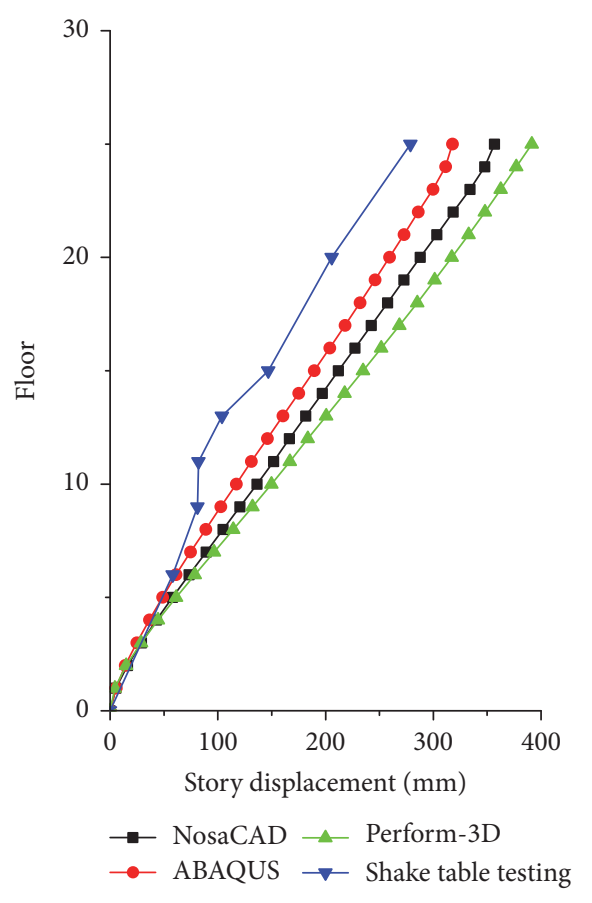

(a) In direction $X$

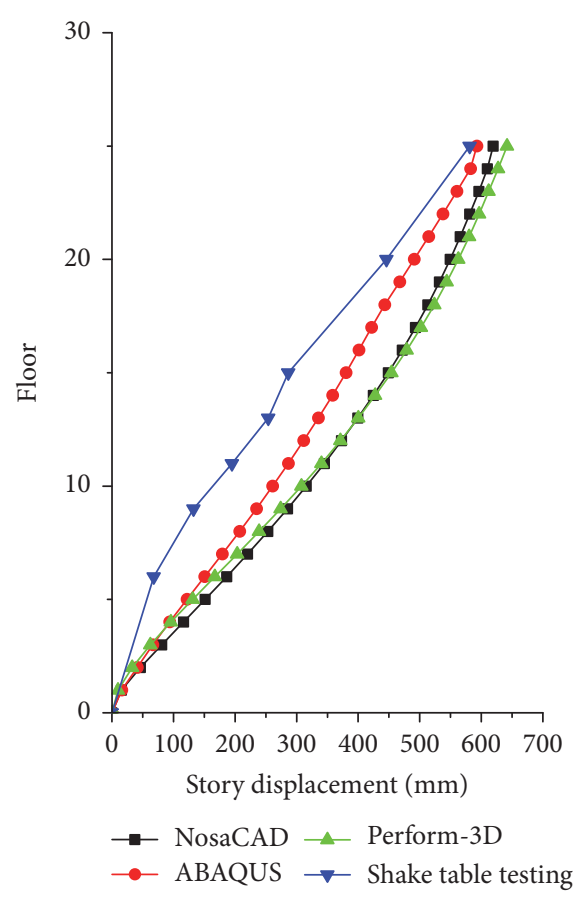

(b) In direction $Y$

FIGURE 18: Story displacement envelopes under rare intensity 7 earthquakes.

connecting floor in finite element analysis under rare intensity earthquakes, the corresponding interstory drift increases obviously and the maximum interstory drift occurs below the connecting floor. In general, the interstory drift in the $Y$ direction is bigger than that in the $X$ direction. The reason can be attributed to the connecting corridor in the $X$ direction, which results in that the lateral stiffness in the $X$ direction is bigger than that in the $Y$ direction.

When the structure suffers minor earthquakes, the maximum interstory drift obtained from NosaCAD, ABAQUS, 


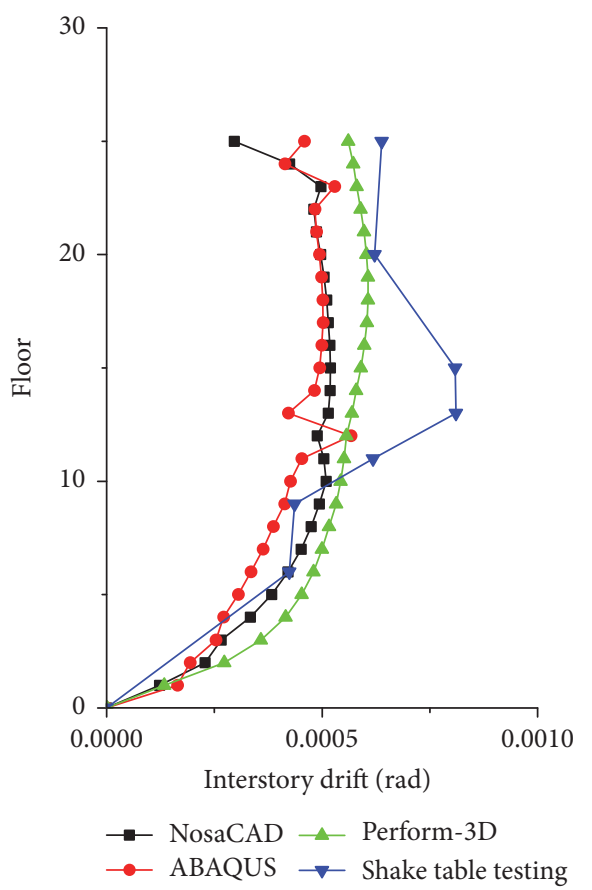

(a) In direction $X$

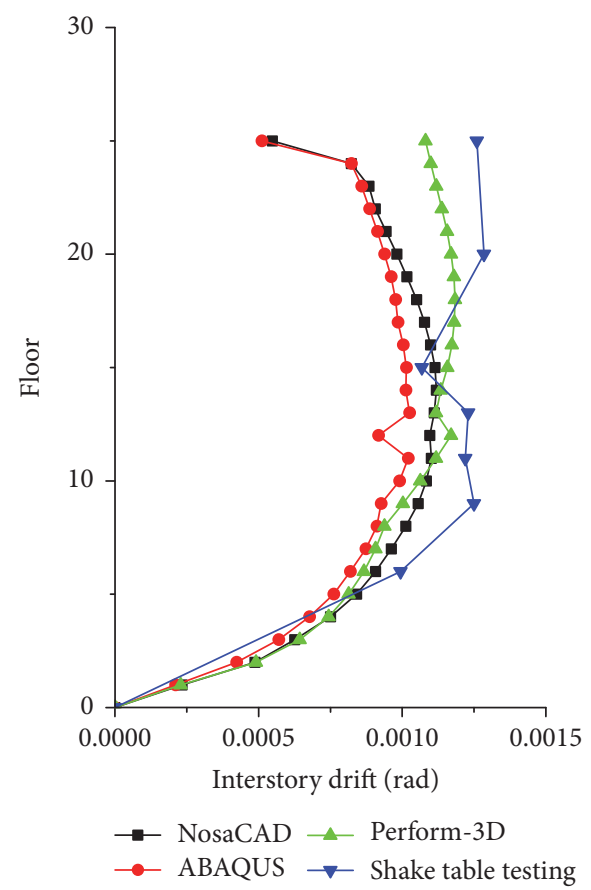

(b) In direction $Y$

FIGURE 19: Interstory drift envelopes under frequent intensity 7 earthquakes.

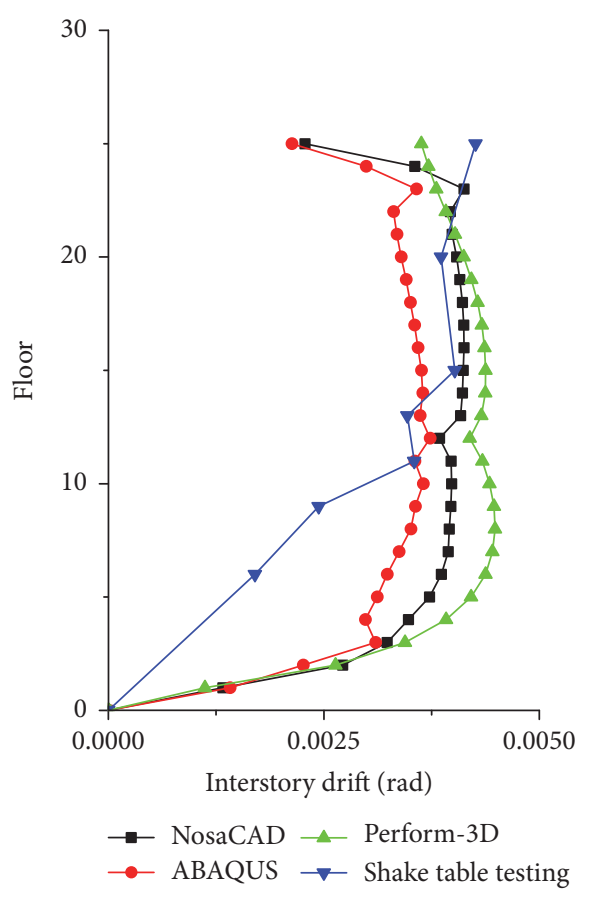

(a) In direction $X$

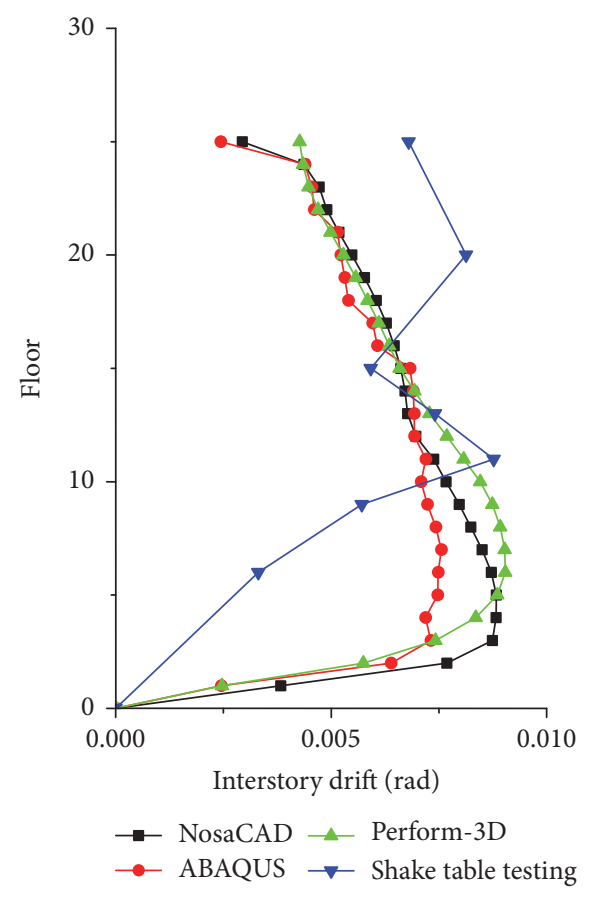

(b) In direction $Y$

FIGURE 20: Interstory drift envelopes under rare intensity 7 earthquakes.

Perform-3D, and experiments in the $X$ direction is $1 / 1926$, $1 / 1763,1 / 1648$, and $1 / 1234$, respectively. The maximum rate of deviation is $35.93 \%$. In the $Y$ direction, the maximum interstory drift is $1 / 893,1 / 971,1 / 847$, and $1 / 778$, respectively, and the maximum rate of deviation is $19.88 \%$. When the structure suffers major earthquakes, the maximum interstory drift obtained from NosaCAD, ABAQUS, Perform-3D, and experiments in the $X$ direction is $1 / 242,1 / 268,1 / 223$, and 


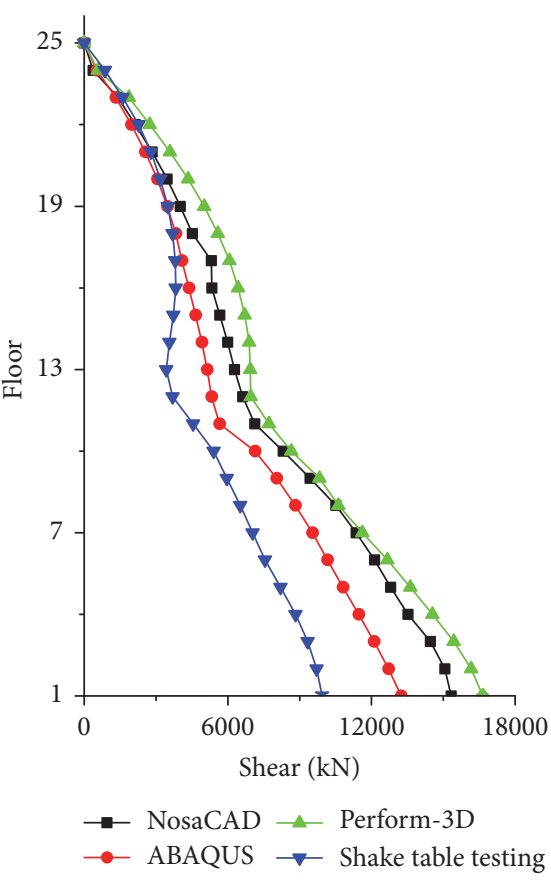

(a) In direction $X$

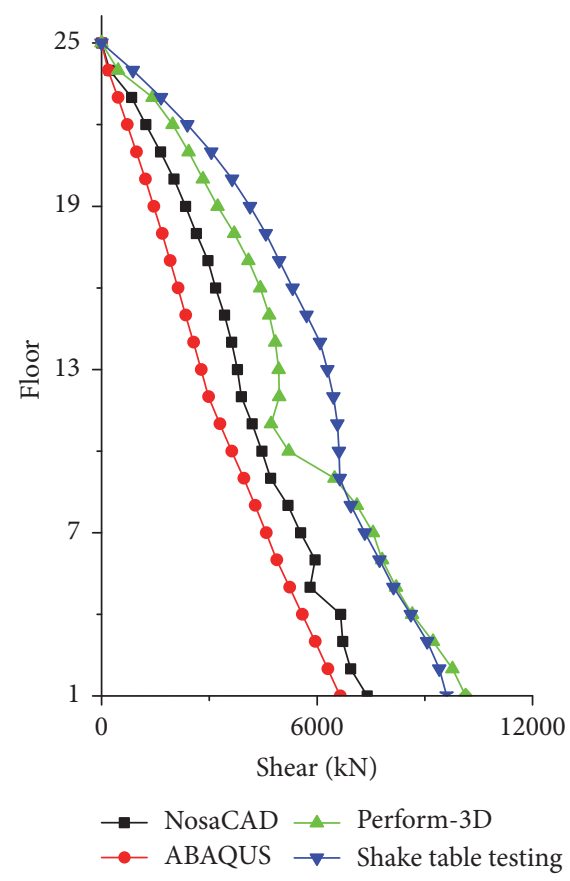

(b) In direction $Y$

FIGURE 21: Story shear envelopes of frequent intensity 7 earthquakes.

$1 / 235$, respectively, and the maximum rate of deviation is $16.79 \%$. In the $Y$ direction, the maximum interstory drift is $1 / 113,1 / 132,1 / 111$, and $1 / 114$, respectively.

The maximum interstory drift from numerical analyses under frequent earthquakes is less than $1 / 800$ that is required by TSCSTB. This value is $1 / 111$ under rare earthquakes. It is less than $1 / 100$ that is required by the code.

4.5. Floor Shear. Figures 21 and 22, respectively, show the floor shear envelopes at minor and major levels. As can be seen in the figures, results of three software programs and experiments in the $X$ direction match each other. The envelope curves regress near the connecting corridor. The reason for this phenomenon may be attributed to the connecting corridor, which in the $X$ direction increases the direction's lateral stiffness, resulting in stress concentration. Deviation exists between numerical and experimental results. In the $Y$ direction, the floor shear force in NosaCAD model under frequent intensity earthquakes is close to that in the ABAQUS model, while results of three software programs match each other under rare intensity earthquakes.

\subsection{Damage Pattern}

4.6.1. Damage in NosaCAD. Because the damage under SHW2 in the $Y$ direction under rare intensity is most severe, the damage under SHW2 in the $Y$ direction was used in illustrating structural damage under rare intensity earthquakes. Figure 23 shows damage patterns in NosaCAD. As can be seen from Figure 23, the coupling beam concrete firstly cracked. The cracked coupling beams belong to the Annex Tower. When time came to 5 seconds, cracks occurred at the bottom of the shear wall. With the increase of earthquake actions, the cracks of the core wall progressively occurred from local to global. The ground acceleration reaches its peak at $6.52 \mathrm{~s}$. At this moment a large number of coupling beams of the core wall came into yielding state, and concrete was crushed at the end of some coupling beams, which mainly occurred at first level to thirteenth level of the Main Tower.

About the same time, the frame beams of the Main Tower, which are located outside the core wall, came to yielding state from the connection floor to the other floors. Some steel beams on third floor to sixth floor reached the ultimate state. Then some boundary restraint elements at the edge of the core tube of the Main Tower yielded. Some core wall concrete on the south of the Main Tower was crushed. The degree of damage of the Annex Tower is smaller than that of the Main Tower. Many frame beams connecting the northern core wall with the southern core wall came into yielding state. About the same time, some boundary restraint elements at the bottom of the core tube near the Main Tower yielded. Most columns remain undamaged and only three columns at the edge of the west of the Main Tower yielded.

The slab of the structure is easy to cause crack or local damage due to its irregularity and opening. In the NosaCAD model, elastoplastic analyses were conducted to analyze structural slab damage. There were no cracks in structural slab under frequent intensity earthquakes. Under rare intensity earthquakes, concrete in some structural slab cracked, which mainly occurred at the floor corner or around the openings. The reinforcement in the slab did not yield, which means that the reinforcement in the slab can meet the requirement of "no yielding under rare earthquakes." The damage patterns of slab and the tension stress envelope 


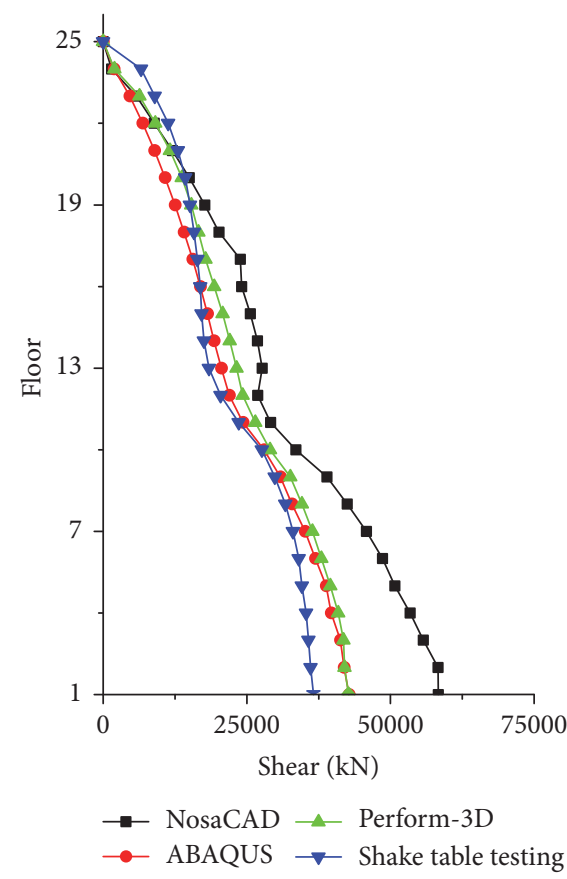

(a) In direction $X$

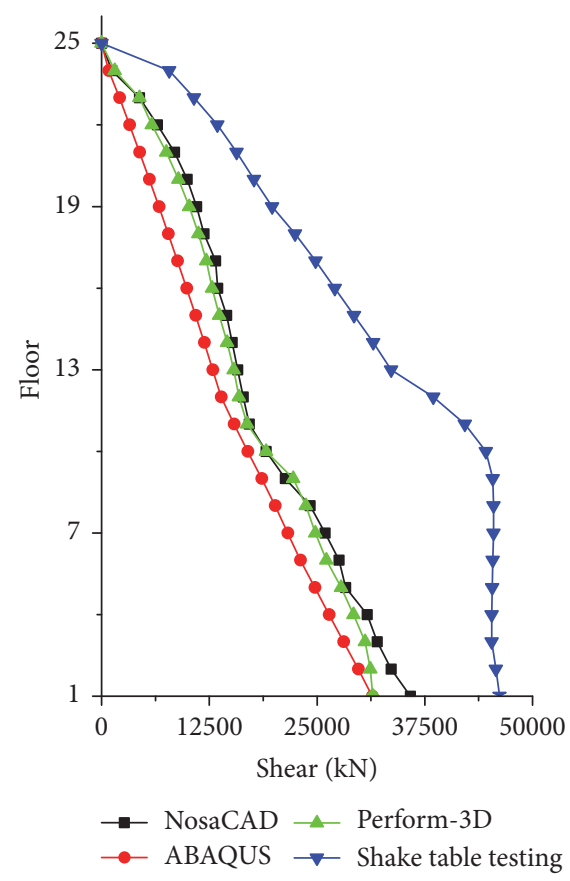

(b) In direction $Y$

FIGURE 22: Story shear envelopes under rare intensity 7 earthquakes.

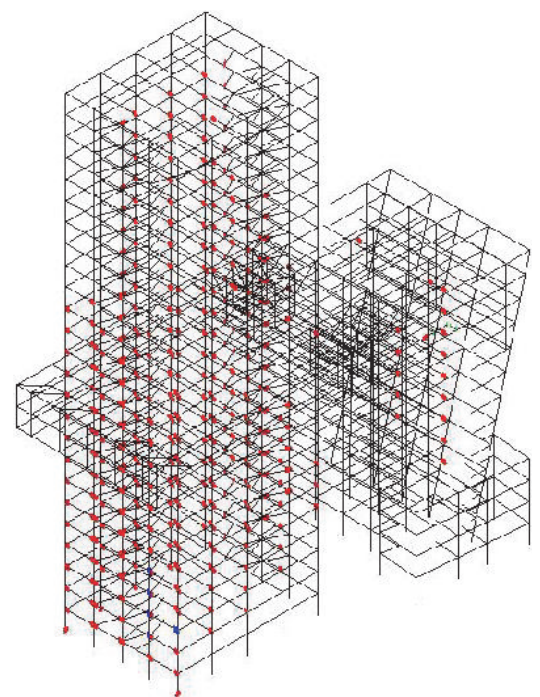

1 - Concrete cracked

- Plastic hinge

- Concrete crushed

(a) Frame beam and column
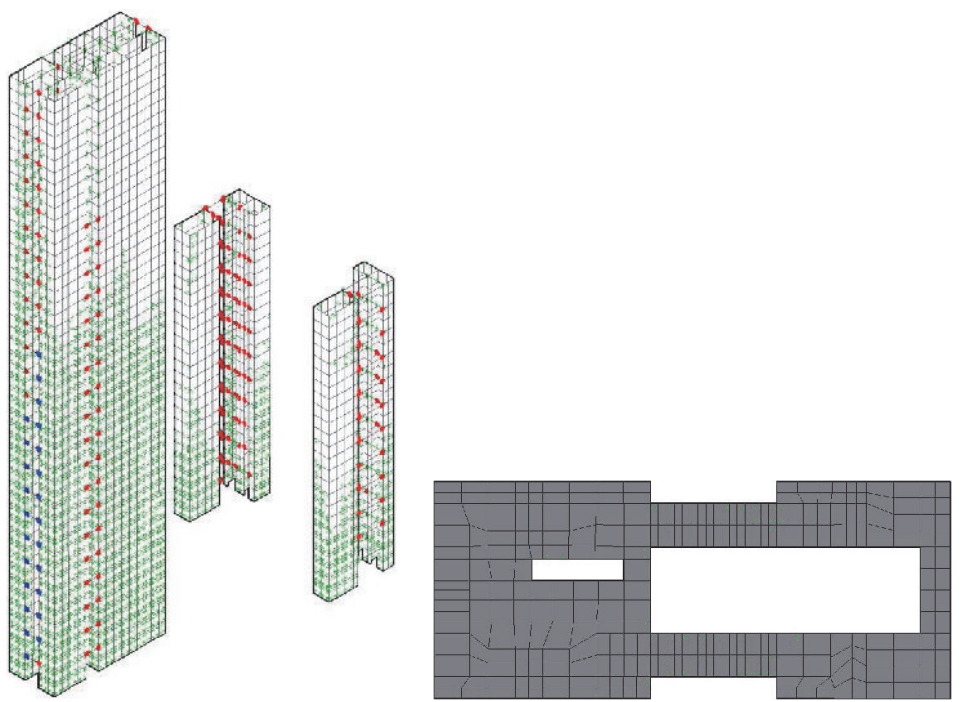

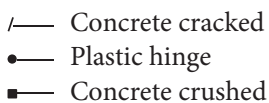

(b) Coupling beam and core wall

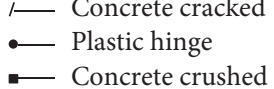

(c) Slab on connecting floor

FIGURE 23: Damage patterns under major earthquakes (NosaCAD).

of reinforcement in the slab on connecting floor under rare intensity earthquakes are shown in Figures 23(c) and 24, respectively.

4.6.2. Damage in ABAQUS. In ABAQUS, the damaged factor was used to study damage situations of concrete in the core wall. Figure 25 shows the core wall damage in ABAQUS. The coupling beam was simulated by the B31 element, for which the damage of coupling beam was not presented. The maximum compressive damage factor is 0.778 , which occurred on the southeast of the Annex Tower. The compressive damage of the exterior core wall at the first floor to the fourth floor, 


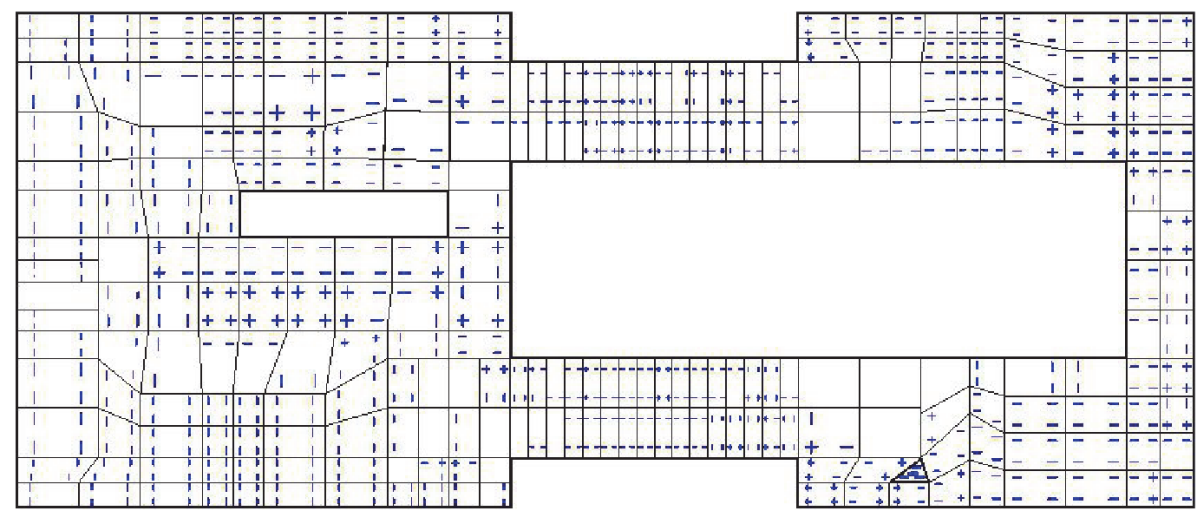

\section{. NosaCAD}

Time: 30.00 (s)

Unit: $\mathrm{N}, \mathrm{Kg}, \mathrm{mm}$
口-24.767003
$\square-173.369024$
$\square-49.534007$
$\square-198.136027$
$\square-74.301010$
$\square-222.903030$
$\square-99.068014$
$\square-247.670034$
$\square-123.835017$
$\square-272.437037$
$\square-148.602020$
口-297.204041

FigurE 24: Tension stress envelopes of the rebar in the slab at the connecting floor under major earthquakes (NosaCAD).

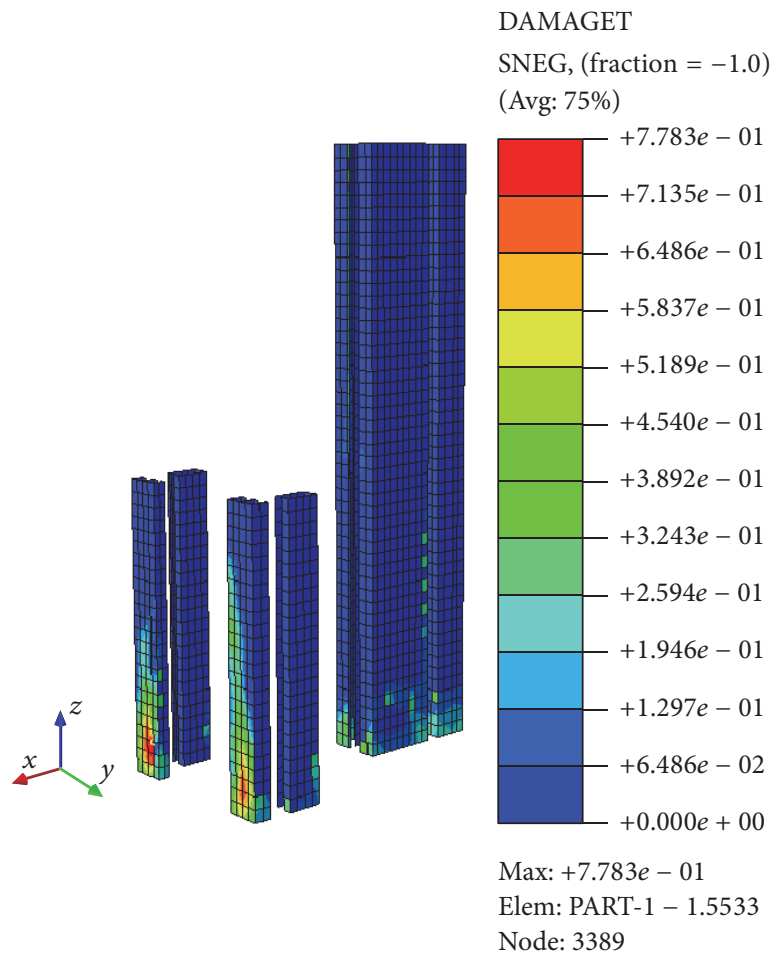

(a) Compressive damage of the core wall
DAMAGET

SNEG, (fraction $=-1.0)$

(Avg: $75 \%)$
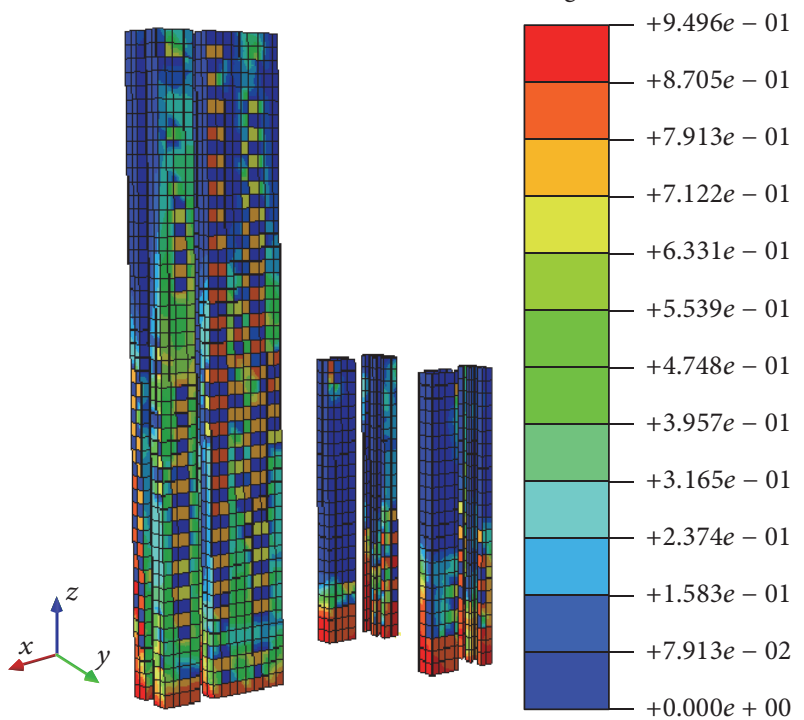

Max: $+9.496 e-01$

Elem: PART-1 - 1.310

Node: 4070

FIGURE 25: Damage patterns of concrete of the core wall under rare intensity 7 earthquakes (ABAQUS). 


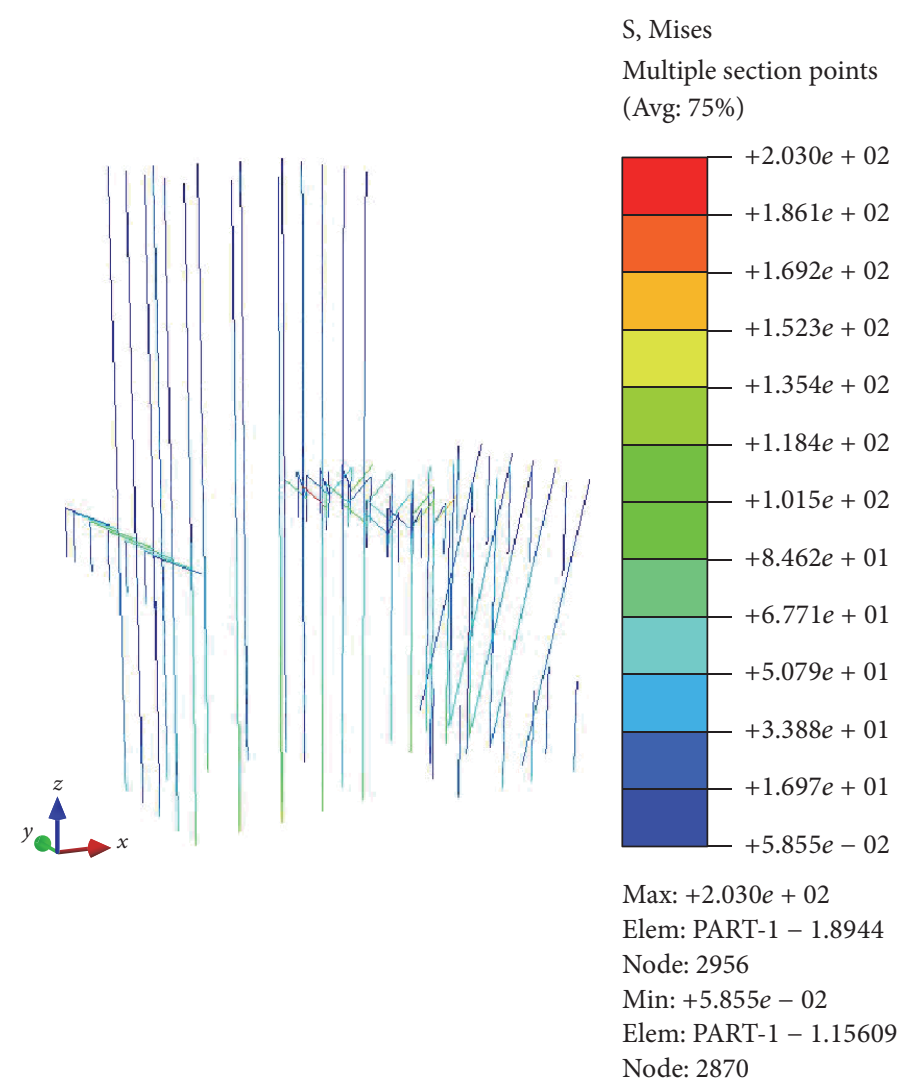

FIGURE 26: Mises stress of the frame columns and belt truss of connecting members under rare intensity 7 earthquakes (ABAQUS).

on the east of the Annex Tower, is relatively severe. The maximum tensile damage factor is 0.950 , which occurred on the northeast of the Annex Tower. The core wall of the Main Tower has different damage situations at different heights, and the damage degree of core wall below the connecting corridor is higher than that of the core wall above the connecting corridor.

The envelope of Mises stress of frame columns and belt trusses of connecting body is shown in Figure 26. The maximum equivalent stress occurring at the tension diagonal of connecting body is $203 \mathrm{Mpa}$, which is smaller than the material yield strength. The Mises stress of frame columns below the connecting body ranges from 0 to $100 \mathrm{Mpa}$, while that above the connecting body is smaller. Because of the lateral stiffness' difference between frame and core wall, most seismic forces were supported by the shear wall.

4.6.3. Damage in Perform-3D. More than half of the frame beams on the Main Tower came into yielding state, which mainly occurred on the west of the Main Tower. All of the columns remain elastic. Two diagonal braces connecting the Annex Tower yielded. A majority of coupling beams came into yielding state. On the Main Tower, some coupling beams in $Y$ direction below the connecting corridor were crushed, and an amount of rebar at the bottom of core wall on the Main Tower yielded. Very few concrete of core wall on the Main Tower nearly came to ultimate state.
The following can be concluded from Figure 23 to Figure 27. (1) The numerical results obtained from three software programs, such as the global response, weak story, and damage condition, show a good agreement. (2) In three software programs, judging from the sequence of damage development, the structural design meets well the principles of "strong column and weak beam" and "strong wall and weak coupling beam." The yield failure was first found in coupling beams which is regarded as the first and major antiseismic component that dissipates a great deal of input energy of rare earthquake. (3) The structure does not collapse under rare earthquakes, which reaches the designing target that is specified in Chinese code.

Because damage results of shake table testing under rare intensity 7 earthquakes were obtained by three earthquake records, it is difficult to determine for which load case the damage happened. The damage from experiments under rare intensity 7 earthquakes was not compared with the numerical results of SHW2 input.

\section{Conclusions and Suggestions}

With the more and more complex irregular buildings being constructed, more structural engineers adopt the elastoplastic finite element approaches to evaluate the seismic performance of structures. For complex response of the irregular buildings, in some circumstances more than one software 


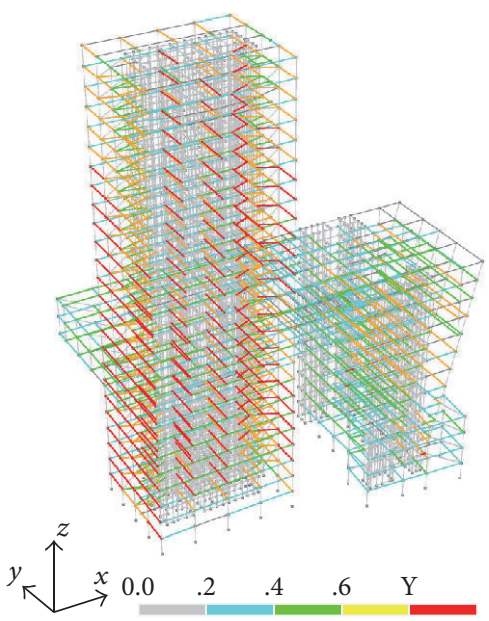

(a) Plastic hinge on frame beam

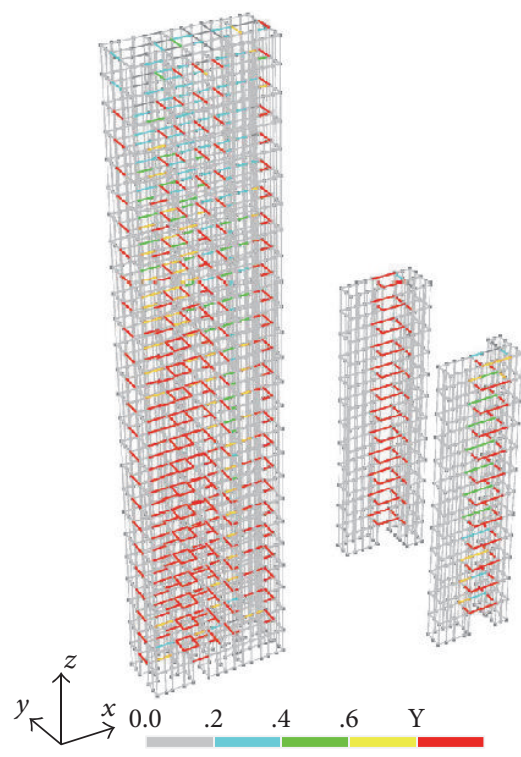

(c) Plastic hinge on coupling beam

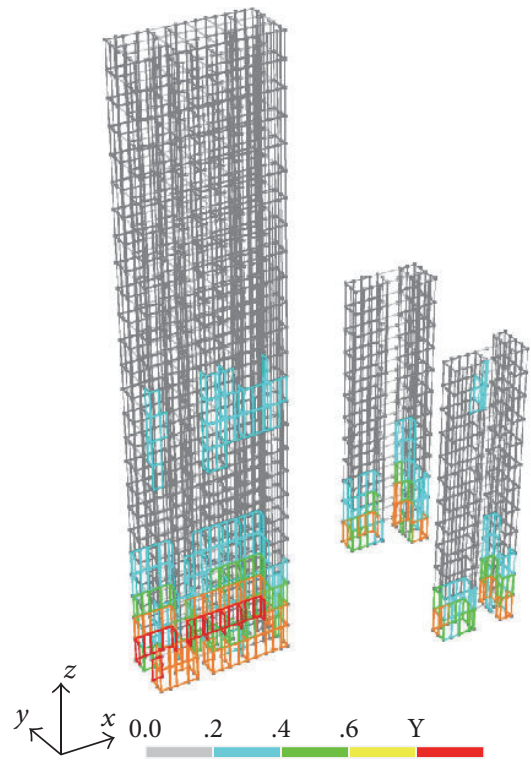

(e) Yielding on rebar of core wall

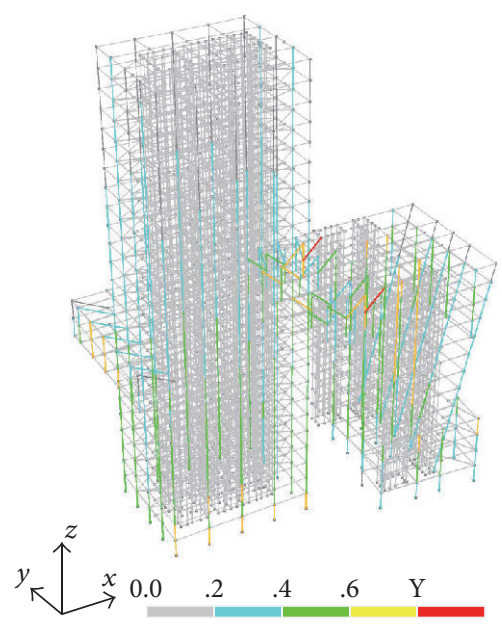

(b) Plastic hinge on column and diagonal brace

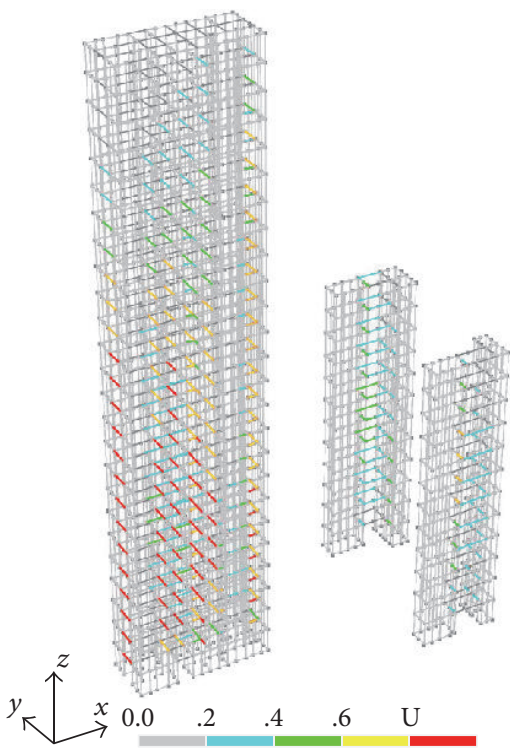

(d) Crushing of concrete on coupling beam

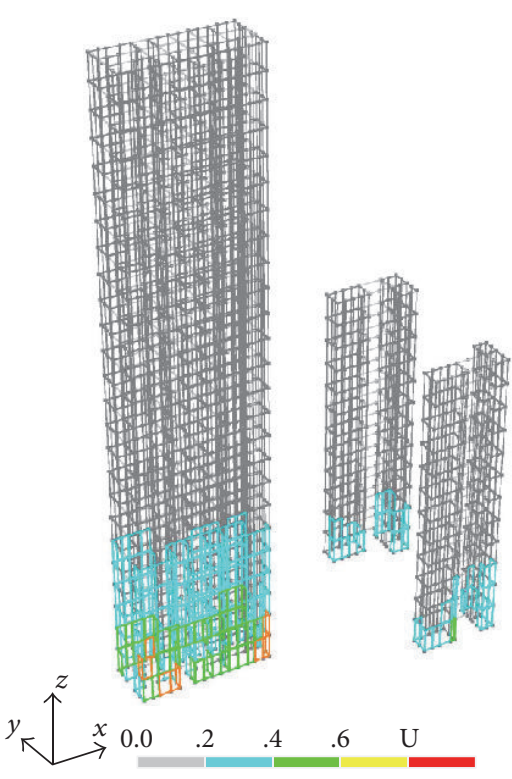

(f) Crushing of concrete on core wall

FIGURE 27: Damage patterns under rare intensity 7 earthquakes (Perform-3D). 
program should be employed to conduct the elastoplastic time history analysis. The NosaCAD has sophisticated function to establish nonlinear model. By the transformation, the elastic and plastic parameters generated by NosaCAD can be shared by structural analysis software ABAQUS and Perform-3D, so that the efficiency of nonlinear analysis can be improved. In this paper, the transformations of elastoplastic model for SHIDC from NosaCAD to ABAQUS and Perform3D were conducted, after which elastoplastic time history analyses were performed. By comparing with shake table testing results, conclusions are summarized as follows:

(1) The model masses for the models from three software programs are nearly identical, as well as the natural vibration periods and vibration modes. Natural periods from numerical analyses are a little different from those of shake table testing, but the sequence of vibration mode in the models of NosaCAD, Perform$3 \mathrm{D}, \mathrm{ABAQUS}$, and experiments is identical. Because of the different lateral stiffness and structural shape between the two towers, the fundamental vibration mode has a torsion composition. Global dynamic characteristics of structure are mainly manipulated by the Main Tower.

(2) The structure almost remains undamaged under frequent earthquakes, which meets the seismic design target. The maximum interstory drift is also less than the limited value. Under frequent earthquakes, the story displacement envelope curves of three FE models are very close to those from the shake table testing, as well as the trend of interstory drift envelope curves. Floor shear envelopes of three numerical models and experiment results in the $X$ direction match each other, while there is some difference in the $Y$ direction.

(3) Under rare intensity earthquakes, calculation results obtained from three software programs match each other, and roof displacement time histories are identical. The interstory drifts obtained from the NosaCAD, ABAQUS, and Perform-3D are all less than the limited value of $1 / 100$. Most supporting members remain undamaged. Hence, the structure does not collapse under rare earthquakes, which meets the seismic design target. The trend of story displacement envelopes of three software programs and experiments shows a good agreement, but there is a little difference in amplitude. The trends of interstory drift envelopes in three software programs and experiments are nearly the same. The interstory drifts of three software programs and experiments in the $X$ direction regress close to the twelfth floor due to the existence of the connecting corridor in the $X$ direction. There is a little difference on the floor shear between numerical results and test results in the $Y$ direction. Some reasons for the difference between numerical results and experiments may fall into errors caused by reduced scale of shake table testing, some inaccuracy of data acquisition, and the lack of consideration on the buckling of steel members in FEM.

(4) Under major earthquakes, damage process of structural members obtained by three software programs is nearly the same. The plastic hinge was first observed in the coupling beams, and then damage occurred on the frame beams. Thereby beam members can help dissipate the input seismic energy, consequently avoiding the damage in the supporting system.

(5) Under rare earthquakes, the structural response of SHW2 in the $Y$ direction is most severe. The most severe damage occurred in the model of NosaCAD. In NosaCAD model, most frame beams on the west of the Main Tower came into yielding state. Some boundary restraint elements at the bottom of core tube of the Main Tower yielded, and some concrete at the core wall of the Main Tower was crushed. The torsional effect is significant, observing from the huge difference between the east and the west of the structure. However, the reinforcement in slab at the connecting floor can meet the requirement of "no yielding under rare earthquakes." It is suggested that the frame beams and boundary restraint elements of shear wall should be strengthened.

In general, the SHIDC design reaches the target of no damage under frequent earthquakes and no collapse under rare earthquakes, which is specified in CSDB.

\section{Competing Interests}

The authors declare that there is no conflict of interests regarding the publication of this paper.

\section{Acknowledgments}

The authors are grateful for financial support received in part from the National Natural Science Foundation of China (Grant no. 51322803) and State Key Laboratory of Disaster Reduction in Civil Engineering (SLDRCE15-B-08). Professor Ying Zhou, who contributed to the research presented here, is also acknowledged.

\section{References}

[1] J. C. L. D. Llera and A. K. Chopra, "Understanding the inelastic seismic behaviour of asymmetric-plan buildings," Earthquake Engineering \& Structural Dynamics, vol. 24, no. 4, pp. 549-572, 1995.

[2] S. Das and J. M. Nau, "Seismic design aspects of vertically irregular reinforced concrete buildings," Earthquake Spectra, vol.19, no. 3, pp. 455-477, 2003.

[3] R. Tremblay and L. Poncet, "Seismic performance of concentrically braced steel frames in multistory buildings with mass irregularity," Journal of Structural Engineering, vol. 131, no. 9, pp. 1363-1375, 2005.

[4] X.-L. Jiang and Y. Han, "Analysis of complex structure eccentric torsion effect in shaking table test," Journal of Vibroengineering, vol. 17, no. 3, pp. 1041-1412, 2015. 
[5] X. Lu, H. Zhang, Z. Hu, and W. Lu, "Shaking table testing of a U-shaped plan building model," Canadian Journal of Civil Engineering, vol. 26, no. 6, pp. 746-759, 1999.

[6] H. Krawinkler, "Importance of good nonlinear analysis," The Structural Design of Tall and Special Buildings, vol. 15, no. 5, pp. 515-531, 2006.

[7] E. Brunesi, R. Nascimbene, and L. Casagrande, "Seismic analysis of high-rise mega-braced frame-core buildings," Engineering Structures, vol. 115, pp. 1-17, 2016.

[8] X. Lu, N. Su, and Y. Zhou, "Nonlinear time history analysis of a super-tall building with setbacks in elevation," The Structural Design of Tall and Special Buildings, vol. 22, no. 7, pp. 593-614, 2013.

[9] A. A. Hedayat and H. Yalciner, "Assessment of an existing RC building before and after strengthening using nonlinear static procedure and incremental dynamic analysis," Shock and Vibration, vol. 17, no. 4-5, pp. 619-629, 2010.

[10] G. Ozdemir and U. Akyuz, "Dynamic analyses of isolated structures under bi-directional excitations of near-field ground motions," Shock and Vibration, vol. 19, no. 4, pp. 505-513, 2012.

[11] A. M. Aly and S. Abburu, "On the design of high-rise buildings for multihazard: fundamental differences between wind and earthquake demand," Shock and Vibration, vol. 2015, Article ID 148681, 22 pages, 2015.

[12] Q.-J. Chen and W.-T. Li, "Effects of a group of high-rise structures on ground motions under seismic excitation," Shock and Vibration, vol. 2015, Article ID 821750, 25 pages, 2015.

[13] P.-C. Nguyen and S.-E. Kim, "Second-order spread-of-plasticity approach for nonlinear time-history analysis of space semirigid steel frames," Finite Elements in Analysis and Design, vol. 105, pp. 1-15, 2015.

[14] X. H. Wu, F. T. Sun, X. L. Lu, and J. Qian, "Nonlinear time history analysis of China Pavilion for Expo 2010 Shanghai China," The Structural Design of Tall and Special Buildings, vol. 23, no. 10, pp. 721-739, 2014.

[15] X. Wu, Y. Sun, M. Rui, M. Yan, L. Li, and D. Liu, "Elastoplastic time history analysis of an asymmetrical twin-tower rigid-connected structure," Computers and Concrete, vol. 12, no. 2, pp. 211-228, 2013.

[16] X. Zha and Y. Zuo, "Theoretical and experimental studies on in-plane stiffness of integrated container structure," Advances in Mechanical Engineering, vol. 8, no. 3, 2016.

[17] C. Xuewei, H. Xiaolei, L. Fan, and W. Shuang, "Fiber element based elastic-plastic analysis procedure and engineering application," Procedia Engineering, vol. 14, pp. 1807-1815, 2011.

[18] Y. Zhou, X. L. Lu, W. S. Lu, and Z. J. He, "Shake table testing of a multi-tower connected hybrid structure," Earthquake Engineering and Engineering Vibration, vol. 8, no. 1, pp. 47-59, 2009.

[19] Ministry of Construction of the People's Republic of China, Code for Seismic Design of Buildings (GB50011-2010), China Architecture and Building Press, Beijing, China, 2010 (Chinese).

[20] Ministry of Construction of the People's Republic of China, "Technical specification for concrete structures of tall building," Tech. Rep. (JGJ3-2010), China Architecture and Building Press, Beijing, China, 2010 (Chinese).

[21] X. H. Wu and X. L. Lu, "Nonlinear finite element analysis of reinforced concrete slit shear wall under cyclic loading," Journal of Tongji University, vol. 24, pp. 117-123, 1996 (Chinese).

[22] Shanghai Government Construction and Management Commission, Code for Seismic Design of Buildings (DGJ08-9-2003),
Shanghai, China, Shanghai Standardization Office, 2003 (Chinese). 


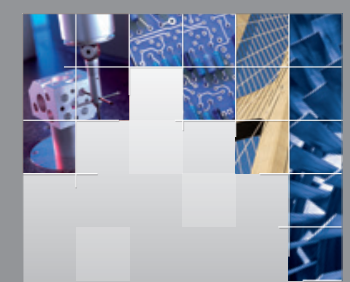

\section{Enfincering}
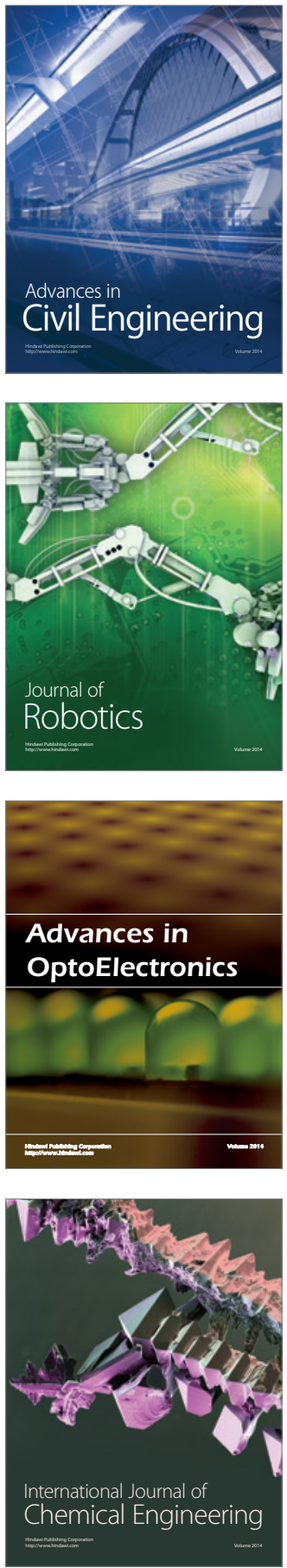

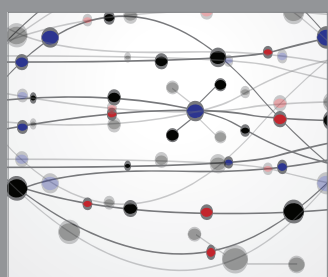

The Scientific World Journal

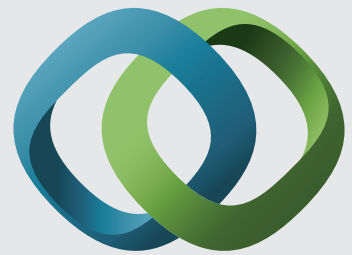

\section{Hindawi}

Submit your manuscripts at

http://www.hindawi.com
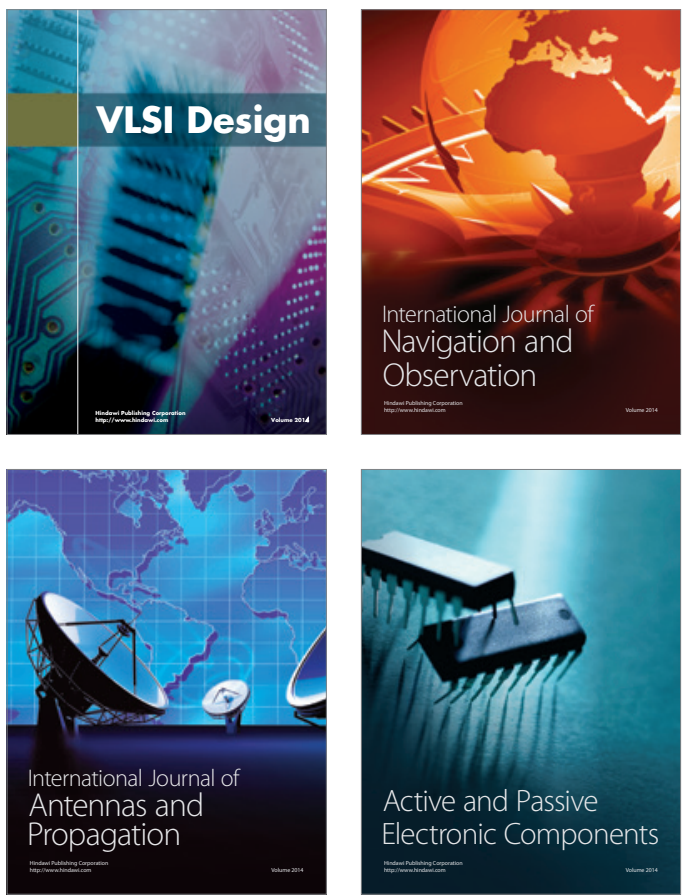
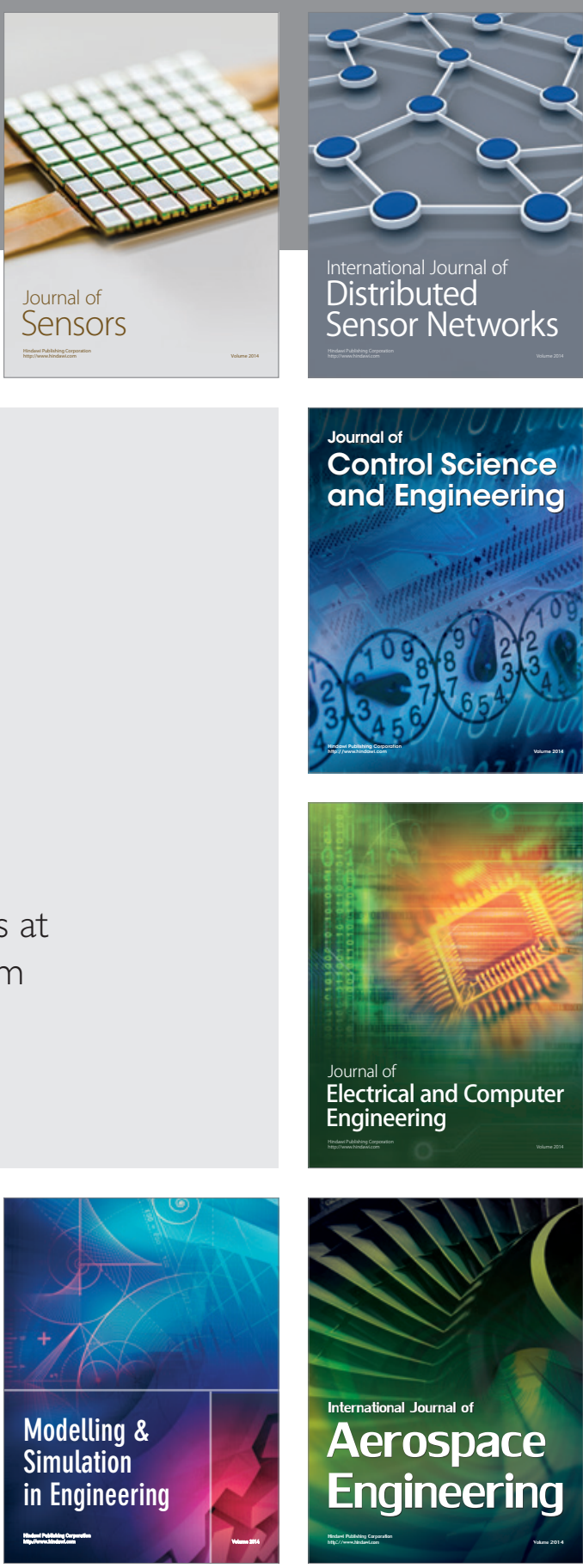

International Journal of

Distributed

Sensor Networks

Journal of

Control Science

and Engineering
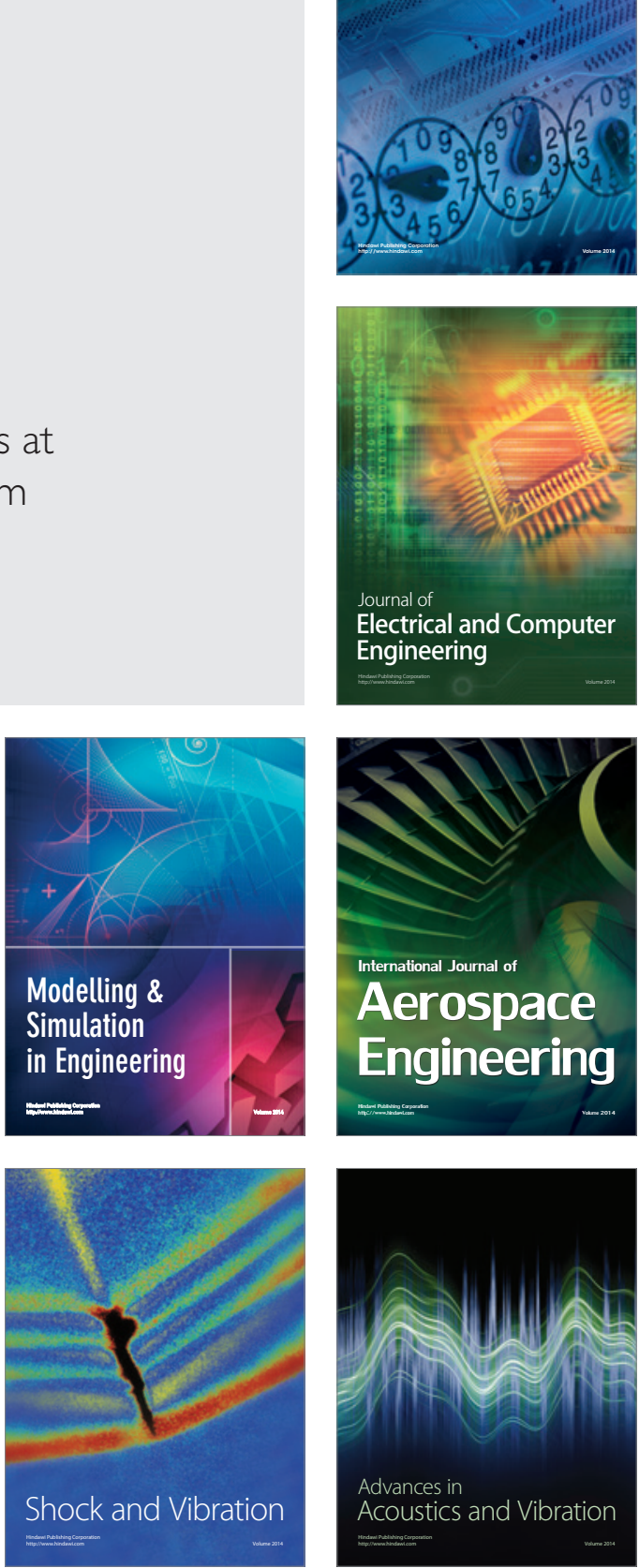